\title{
Existe rima de vogal aberta com vogal fechada na poesia trovadoresca galego-portuguesa?'
}

\author{
José-Martinho Montero Santalha \\ Universidade de Vigo
}

\begin{abstract}
Resumo:
Alguns estudiosos da poesia trovadoresca galego-portuguesa sugeriram que existem nela casos de rima de vogais $e$ ou $o$ abertas com as respectivas fechadas. $\mathrm{O}$ artigo analisa as possíveis ocorrências de tal rima e conclui que não há fundamento seguro para tal afirmação.

Palabras chave:

Poesia trovadoresca, rima, fonética histórica.

Abstract:

Some scholars suggested that in the medieval Galician-Portuguese poetry appear some cases of rhyme of open and closed $\mathrm{e}$ and o vowels. The article analyses the possivel cases of such a rhyme and concludes that there is no sure basis for that assertion.
\end{abstract}

Key words:

Mmedieval Galician-Portuguese poetry, rhyme, historical phonetics.

\section{Introdução}

Uma das mais conhecidas aplicações filológicas da análise do artifício das rimas na poesia trovadoresca é a que diz respeito ao estado em que se achava nos séculos XIII-XIV o vocalismo de grau médio; isto é, as duas parelhas de fonemas vocálicos conhecidos comummente como $e$ e $o$ abertos e fechados (que em transcrição fonológica se representam habitualmente como /ع/, /e/, por uma parte, e, por outra, / /, /o/, signos que correspondem, no sistema ortográfico português, às grafias é, ê, ó, $\hat{o}$ respectivamente quando claramente caracterizadoras) ${ }^{2}$.

Em geral, a gramática histórica permite-nos conhecer, partindo dos étimos latinos, qual deveu de ser, para essas vogais de grau médio, o timbre vocálico primitiva-

Recolho aqui sinteticamente os pontos principais relativos a este tema que aparecem em diversos apartados da minha tese de doutoramento sobre as rimas da poesia trovadoresca (Montero Santalha 2000).

2 Para a época medieval careceria de sentido pôr-se a questão da distinção entre os dous fonemas /a/ e $/ \alpha /$ existentes hoje no português de Lisboa e do centro de Portugal (e, por influxo da língua da capital, 
mente resultante, aberto ou fechado. Mas se dermos um salto desde essa situação originária até a época moderna, descobriremos que a língua actual nos oferece abundantes modificações do timbre que se supõe primitivo: algumas vogais que deveram de ser originariamente abertas passaram a fechadas, e viceversa.

Por exemplo, o substantivo medo, hoje com ê tónico fechado /e/ na maior parte do nosso território lingüístico, deveu de ser primitivamente com é /ع/, pois assim corresponde ao étimo latino MĔTUM e assim se mantém ainda no falar conservador da zona oriental da Galiza (cfr. igualmente o resultado ditongado castelhano miedo); houve, pois, no decurso da história da língua um fechamento do timbre aberto originário.

Inversamente, o pronome pessoal ela apresenta hoje é tónico aberto /ع/ na língua comum, mas originariamente deveu de possuir $\hat{e}$ /e/ de acordo com a etimologia (< lat. ILLLAM) e com a actual pronúncia de algumas zonas mais conservadoras.

$\mathrm{O}$ interesse das rimas trovadorescas a este respeito reside em que a análise comparativa das diversas palavras rimantes de uma mesma rima pode permitir-nos deduzir o grau de abertura vocálica então existente, e conseguintemente pode ajudar-nos a estabelecer a cronologia dessas mudanças fonéticas.

Ora, uma dedução dessa natureza parte do pressuposto de que as rimas trovadorescas mantinham escrupulosamente, para as palavras rimantes de uma mesma rima, a identidade de timbre das vogais de grau médio; isto é, que os trovadores não admitiam a rima de vogal aberta com vogal fechada, contrariamente ao que vem acontecendo na poesia moderna.

Eis, pois, o problema que nos pomos aqui: merecem confiança as rimas trovadorescas neste ponto? Dito com outras palavras: mantinham os trovadores a plena homofonia rimática ou, pelo contrário, faziam rimar vogal aberta com vogal fechada?³.

\footnotetext{
também na fala culta de falantes do resto do país), mediante os quais se distinguem as desinências -amos da P4 do presente de indicativo e do perfeito dos verbos da $1^{\mathrm{a}}$ conjugação (por exemplo, amamos e amámos, respectivamente): na poesia trovadoresca rimam todas elas indistintamente em amos, o que parece indicar que na língua da época ambas as formas possuíam o mesmo timbre da vogal tónica. Tratava-se seguramente do timbre aberto, etimológico, conservado ainda na pronúncia popular das áreas mais conservadoras (Galiza e Norte de Portugal). Veja-se, por exemplo, Maia (1986: 313-319).

3 A este respeito, algo de dúvida pode suscitar nas Cantigas de Santa Maria o facto de o rei Afonso x não ter como língua nativa o galego-português (e talvez nem sequer como língua de infância, pois a estadia infantil em terras galegas que se tem suposto não está confirmada documentalmente; e, mesmo no caso de ter existido, deveu de ser breve, talvez não superior a um ano). Do mesmo modo que os trovadores catalães e italianos em provençal se sentiam desviados na sensibilidade perante a abertura vocálica pela sua língua nativa, do mesmo modo a um falante de castelhano tinha que resultar embaraçosa, já no século XIII, a diferença galego-portuguesa entre as vogais de grau médio. De resto, como se sabe, é incerto em que medida o próprio rei foi autor das composições (assim das CSM como das cantigas profanas que aparecem sob o seu nome); parece lógico atribuir a maior parte do trabalho de redacção, pelo menos no seu aspecto mais directamente lingüístico, aos trovadores de fala galego-portuguesa presentes na sua corte, entre os quais deviam de ser especialmente numerosos os galegos, por ser o território da Galiza um "reino" englobado nos seus domínios.
} 
Antes de mais será conveniente revisar as principais opiniões que se têm manifestado sobre o assunto, o que nos permitirá advertir alguns errores que é preciso evitar, para logo intentar descobrir se da análise do conjunto das rimas dos nossos trovadores se podem deduzir alguns indícios de qual devia de ser a sua atitude geral ao respeito.

\section{Algumas opiniões}

Vejamos que opiniões se têm manifestado acerca deste assunto pelos estudiosos do nosso trovadorismo.

Rodrigues Lapa. Rodrigues Lapa, no seu estudo «O texto das cantigas d' amigo», aparecido em 1929 -que é uma pormenorizada recensão da edição das cantigas de amigo de Nunes publicada nos anos precedentes (Nunes 1926-1928)-, fala, embora de passagem (pois está tratando da "mistura de vogais nasais com orais"), de "um facto, que deveria arrepiar a susceptibilidade métrica dos trovadores: a rima de vogais abertas com fechadas" (Lapa 1982: 150).

Como se pode ver, Lapa parece dar por seguro que os trovadores de nenhum modo admitiam a rima de abertas com fechadas.

Celso Cunha. Neste ponto, como noutros relativos à técnica versificatória dos nossos trovadores, tem exercido especial influxo a opinião do investigador brasileiro Celso Cunha, que estudou demoradamente alguns aspectos da versificação trovadoresca. Manifestando o seu desacordo com essa breve afirmação de Lapa, Cunha, no seu estudo «Rima de vogal oral com vogal nasal», afirmou -ainda que também de passagem e em nota de rodapé- que na nossa poesia trovadoresca ocorria a rima de vogal aberta com vogal fechada, embora não muito freqüentemente:

Embora não muito freqüentes, não faltam, na poesia trovadoresca, exemplos de rima de vogal aberta com vogal fechada, como em boa hora mostrou A. Mussafia, em Sull' antica metrica portoghese (Cunha 1982: 172, nota 7).

Cunha não assinala aí exemplos ou referências precisas às cantigas em que se daria esse fenómeno, e limita-se a enviar o leitor, como se vê, para o clássico artigo de Adolfo Mussafia sobre a antiga métrica portuguesa publicado originariamente em 1896 (Mussafia 1983). Este trabalho de Mussafia tornou-se, merecidamente (e apesar da sua relativa brevidade), um dos estudos clássicos sobre alguns aspectos formais do nosso trovadorismo (nomeadamente sobre a conhecida ainda hoje como «lei de Mussafia»). Ora, afirma Mussafia realmente que na nossa poesia trovadoresca se dá rima de vogal aberta com vogal fechada? 
Na verdade, cumpre antes de mais advertir que Mussafia se ocupou só incidentalmente deste aspecto (que não era o objecto central do seu artigo, mas um ponto marginal): tratou dele no primeiro dos dous apêndices com que enriqueceu o trabalho, com o ensejo de fazer notar a chamada "rima partida" "“Appendice Ia. Rima spezzata. Vocali aperte e chiuse": Mussafia 1983: 330-335; sobre este ponto, 332$335)$.

Em primeiro lugar, Mussafia ocupa-se da cantiga de amor de Dom Denis «Assi me

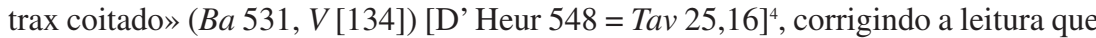
dela dá Henry Lang na sua -então recente, e, em geral, excelente- edição das cantigas de Dom Denis (Lang 1894: 49): Lang não percebera que Dom Denis emprega nesta composição o artifício das palavras divididas em fim de verso a fim de fazer rimar uma sílaba interior; e Mussafia precisa que ocorrem na cantiga as rimas ór e $\hat{o} r$, independentes entre $\mathrm{si}^{5}$.

Como voltaremos a encontrar-nos ainda com esta cantiga mais adiante, pode ser útil apresentarmos aqui o seu texto completo ${ }^{6}$ :

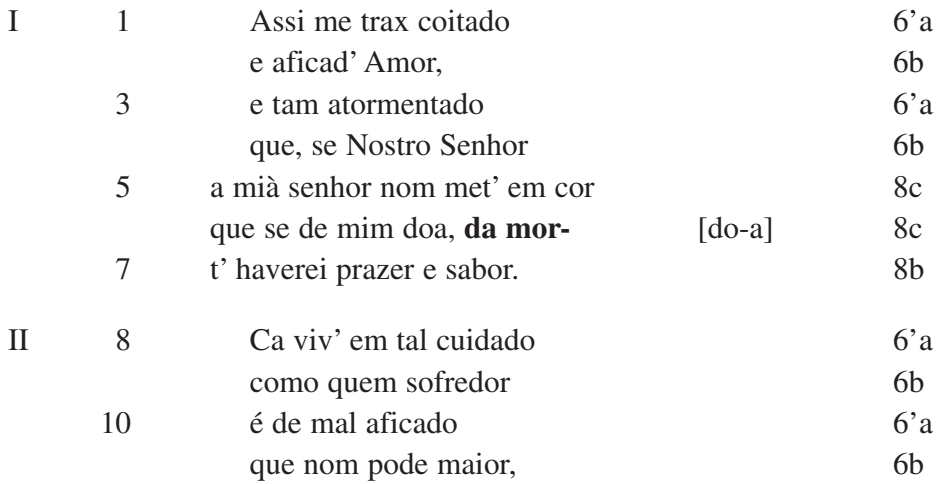

4 Uso como sistema de referência às cantigas trovadorescas a numeração do catálogo de D’Heur (1973), que considero preferível à de Tavani (1967), embora também indique habitualmente a equivalência nesta. Para integrar as Cantigas de Santa Maria nessa mesma série numérica das cantigas profanas, optei por assignar-lhes um número a partir do 2000 -não alcançado pelo catálogo de D’Heur, que chega só a 1683-, conservando nas três últimas cifras o seu número habitual (tal como aparece na edição de Mettmann).

5 Essa cantiga foi depois correctamente editada por Nunes entre as cantigas de amor (Nunes 1932: $162-$ 163, cantiga 80), e é lástima que os organizadores de Lírica profana (Brea 1996: 183, cantiga 25,16) optassem por reproduzir ainda a edição de Lang, claramente insatisfactória; logicamente, em correspondência com esse texto, as fórmulas rimáticas propostas (três diferentes, uma para cada estrofe) resultam também inadequadas.

6 Assinalo em negrito o artifício da «palavra-rima» no sexto verso de cada estrofe (da mor-), já observado por Mussafia, o qual vem a confirmar a estrutura métrica da composição. 


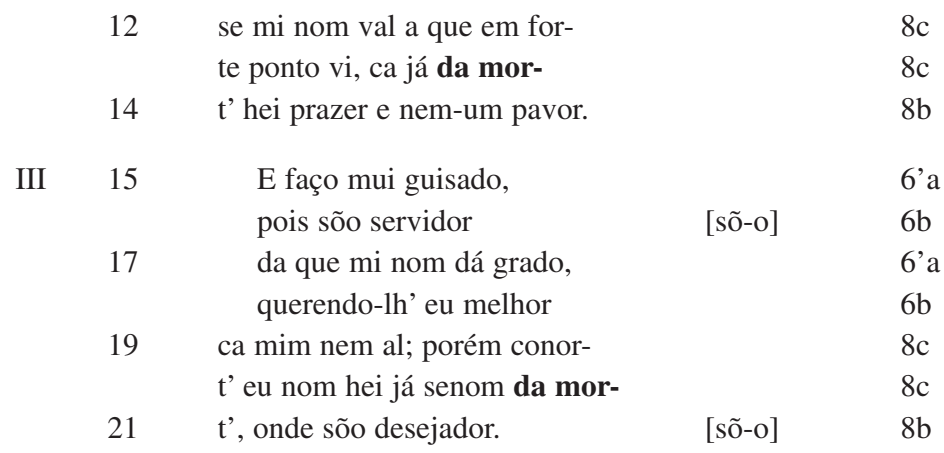

A fórmula rimática é ]ababccb[. A rima ]b[ é ôr, enquanto a rima ]c[ é ór. Rimam em ôr: Amor, Senhor, sabor, sofredor, maior, pavor, servidor, melhor, desejador. Rimam em ór: cor e as palavras divididas mor-[te] (que aparece como palavra rimante em todas as estrofes no mesmo verso: o artifício poético conhecido como «palavra-rima»), for-[te] e conor-[te].

Em segundo lugar, aproveitando a oportunidade oferecida por esse texto, Mussafia ocupa-se do assunto da abertura vocálica em rima: "E qui viene in acconcio fare un'altra osservazione rispetto alla distinzione in rima delle vocali aperte dalle chiuse" (Mussafia 1983:332). E assim rectifica algumas fórmulas rimáticas de Lang, notando como confundira as rimas ér e êr, e ésse e êsse, sem distinguir entre vogais abertas e fechadas; e a este propósito, centrando a sua atenção nas formas verbais fortes e débeis, observa como os nossos trovadores mantinham nas rimas a homofonia do timbre vocálico, em contraste com o que fazem os poetas modernos:

nell' antica poesia portoghese le forme forti non rimano mai con le deboli, mentreché nella poesia posteriore questa distinzione non viene piú osservata. E ciò non avviene perché in via fonetica la diversità di pronuncia sia cessata [...], ma perché la poesia moderna rinunciò alla distinzione fra le due $e$ e le duo $o$. E poiché si tratta di fonetica, e non di morfologia, s' intende da sé che nell' antica poesia la distinzione non si ristringa alle forme verbali (Mussafia 1983: $333)$.

Mussafia aduz logo os testemunhos doutras cantigas em que segundo as edições de Varnhagen e Teófilo Braga podia haver dúvidas a esse respeito, e faz observações de grande inteligência filológica, tomando como ponto de referência as rimas das $C S M$ e perguntando-se se nalguma passagem dessas edições em que parece não coincidir o timbre vocálico das rimas não haveria erro (como efectivamente acontece). 
Em conclusão, Mussafia não afirma que existam na nossa poesia trovadoresca rimas de vogal aberta com vogal fechada; antes ao contrário, perante as dúvidas suscitadas por alguma passagem esporádica, põe de manifesto a regularidade da distinção entre os nossos trovadores. E acaba exprimindo o seu desejo de que alguém se decida a estudar exaustivamente esse assunto: "Farebbe opera utile chi studiasse la questione concernente le rime di vocali aperte e chiuse dai primordi della poesia portoghese fino ai dí nostri” (Mussafia 1983: 335).

Parece, pois, que Celso Cunha deveu de sofrer alguma confusão ao pretender fundamentar no artigo de Mussafia a afirmação de que existe rima de vogal aberta com fechada na poesia trovadoresca, ou talvez formulou a sua afirmação de maneira excessivamente esquemática: como vemos, Mussafia diz mais bem o contrário do que Cunha parece querer atribuir-lhe.

A reedição do estudo de Cunha em que aparecia a frase comentada, na sua miscelânea sobre a versificação medieval (Cunha 1982), tornou bem conhecido esse texto entre os interessados pelos problemas da técnica versificatória dos trovadores. E a partir daí, outros estudiosos do nosso trovadorismo, fiados no bem fundado prestígio intelectual de Cunha, e baseando-se somente na citada frase marginal, têm assumido como segura a afirmação de que existe na nossa poesia trovadoresca rima de vogal aberta com vogal fechada?

Ora, Cunha parece ter mudado de opinião sobre este assunto posteriormente, pois num artigo publicado em 1988 (faleceu em 1989) diz partir "do pressuposto, pacificamente aceito pelos especialistas, de que na versificação dos séculos XIII e XIV a homofonia rímica era rigorosa" (Cunha 1988: 221), e declara que o hábito de rimar na nossa língua vogais abertas com fechadas surgiu só no século XVI com Gil Vicente, provavelmente sob influência castelhana ${ }^{8}$.

7 Assim, Antonia Víñez e Juan Sáez no anúncio do seu rimário das cantigas de amigo (Víñez / Sáez 1997) declaram ter reservado uma atenção diferençada para as rimas de vogal aberta com vogal fechada. Eis algumas expressões que dizem respeito a este tema: "para el primero [isto é, Celso Cunha], la alternancia de vocales orales / nasales, al igual que la de vocales abiertas / cerradas en posición de rima, son recursos [...]” (Víñez / Sáez 1997: 1592), “[...] cantigas de amigo presentan casos de asonancia, excluyendo los casos de rima oral / nasal y los que presentan rimas de vocales abiertas con cerradas" (Víñez / Sáez 1997: 1592, nota 14), "hay casos de asonancia, de rimas entre orales y nasales o entre vocales de distinto timbre, como ya ha sido señalado" (Víñez / Sáez 1997: 1595).

8 “A partir da obra de Gil Vicente (1502-1536?), o estudo da ortoépia baseado na rima dos poetas exige a maior cautela, pois o grande dramaturgo português introduziu o hábito de rimar vogais abertas com fechadas, provavelmente por influência do castelhano, em que, ao contrário do nosso idioma, tais vogais não se opõem fonologicamente" (Cunha 1988: 229-230). Reafirma a mesma ideia em artigo aparecido postumamente: "Foi, em verdade, o grande dramaturgo português -provavelmente influenciado pelo sistema fonológico do espanhol, que não opõe /e/ a / $/$ / nem /o/ a / / / quem introduziu na versificação portuguesa a liberdade de rima entre vogais tônicas abertas e fechadas, liberdade que se estendia também aos ditongos" (Cunha 1991: 923). 
Mattoso Câmara. Também Mattoso Câmara, analisando a aplicação da fonologia ao fenómeno da rima, admitiu que na poesia trovadoresca se dava pelo menos algum caso de rima de vogal aberta com fechada, embora reconhecesse que esse tipo de rimas eram "de todo esporádicas na lírica arcaica portuguesa dos séculos XIII e XIV"; e acrescentava:

o exemplo menos discutível é a cantiga $n^{\circ} .134$ do Cancioneiro da Vaticana $\left(n^{\circ} 531\right.$ do Cancioneiro da Biblioteca Nacional de Lisboa), onde D. Dinis rima cor, mor(te), for(te) -com /ó/ aberto, porque saídos de um /o/ breve latino- com senhor, sabor, maior, onde /ô/ fechado corresponde a /o/ longo latino (Câmara 1977: 112).

Como se vê, o exemplo que Mattoso Câmara aduz como "menos discutível" sabemos já que é falso: trata-se da mesma cantiga de Dom Denis que antes vimos, cuja estrutura rimática Mussafia já determinara, advertindo que os dous grupos de rimas citados, ór e ôr, são independentes entre si.

A conclusão geral que pode deduzir-se destas opiniões é que, na poesia trovadoresca, a rima de vogais abertas com fechadas, em caso de realmente existir, é fenómeno excepcional.

Com efeito, a impressão óbvia que a leitura dos trovadores produz é que a grande maioria das rimas guardam a coincidência de timbre. Mas também é verdade que, de uma análise mais demorada, em algumas rimas trovadorescas podem surgir dúvidas a respeito da estrita homofonia no timbre vocálico. Será preciso, pois, que prestemos atenção a esses casos problemáticos.

\section{Duas bases falsas}

Começaremos advertindo que alguns argumentos que poderiam levar a defender a existência de rima de vogal aberta com vogal fechada partem de falsos supostos e carecem de fundamento. Podemos referir-nos brevemente a duas dessas fontes de erro:

1) leituras erradas dos textos, e

2) fórmulas rimáticas incorrectas por errónea interpretação fonológica das rimas.

\subsection{Leituras erradas}

Já vimos que alguma das afirmações de que na poesia trovadoresca existia rima de vogal aberta com vogal fechada baseava-se na edição errada de uma cantiga de Dom Denis.

Pode ainda citar-se algum outro exemplo de edição incorrecta que poderia induzir à mesma falsa conclusão. A cantiga de escárnio do rei Afonso X o Sábio «Senhor, 
justiça viímos pedir» (Bb 483, $V$ [66]) [D’Heur 481 = Tav 18,41] apresenta vários problemas textuais, para os quais, como sempre, Rodrigues Lapa na sua edição das cantigas burlescas propõe leituras bem fundadas, embora possam ser naturalmente discutíveis (Lapa 1970: 21-22). Ora, na terceira estrofe, nos versos 19-20 as palavras rimantes seriam respectivamente despendeu (que, como todas as formas de P3 do perfeito dos verbos da $2^{\text {a }}$ conjug., possui rima em $\hat{e} u$ /ew/) e o pronome pessoal $e u$

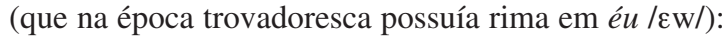

20 e deu, dali foi, - tod' aquesto sei eu

Porém, esta combinação rimática seria tanto mais surpreendente quanto que, sendo a cantiga de rima unissoante, nos correspondentes versos (isto é, quinto e sexto) das outras duas estrofes as palavras rimantes são judeu (v. 5) e romeu (v. 6) na estrofe primeira, e, na segunda, lheu (v. 12) е seu (v. 13): todas palavras com rima éu/عw/. Daqui temos de concluir, como já notou Celso Cunha (Cunha 1991: 914-915), que a palavra rimante do v. 19 não pode ser despendeu; deve de ser deu, pois Lapa fez erradamente a partição dos versos (a qual nos mss. aparece também confusa nessa passagem). Eis, para que possa ver-se a cantiga no seu conjunto, a minha edição completa:

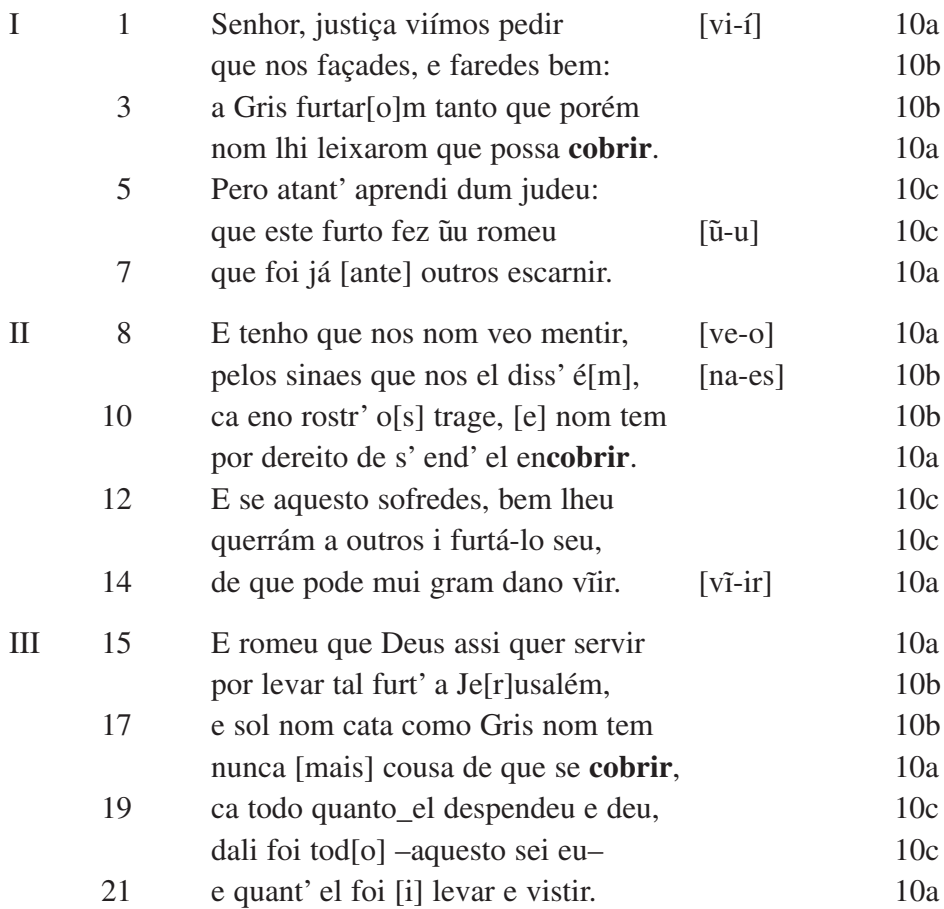




\subsection{Fórmulas rimáticas erradas}

Tem havido também outro tipo de erro que, embora sem afectar agora o texto das cantigas, poderia igualmente fazer crer que os trovadores misturavam em rima vogal aberta com vogal fechada. Neste caso trata-se de uma incorrecta análise da estrutura rimática: alguns estudiosos têm oferecido, para algumas cantigas, esquemas rimáticos que incorrem na mesma confusão que Mussafia denunciava em Lang: identificar como uma única rima parelhas de rimas que se distinguem somente pelo timbre vocálico, aberto e fechado.

Vejamos algumas amostras.

Já foi atrás assinalado que Nunes editou correctamente a cantiga de amor de Dom Denis antes comentada; no entanto, oferece uma fórmula rimática incorrecta, com confusão das duas rimas ôr e ór: ababbbb (Nunes 1932: 163).

Outros editores, especialmente italianos, caem no mesmo erro ao catalogar as rimas. Por exemplo, Valeria Bertolucci, na sua edição das poesias de Martim Soárez (Bertolucci 1963), confunde numa única rima er a parelha bem diferençada ér e êr, e igualmente em $e u$ a parelha éu e $\hat{e} u^{10}$.

Na enumeração das rimas que faz no seu Repertorio metrico Tavani distingue bem entre as rimas ér e êr, mas não entre outras parelhas de rimas como éu e êu, ou ór e ôr; a consequência desta confusão é que as fórmulas rimáticas resultantes são por vezes erradas ${ }^{11}$.

Antonia Víñez, no seu rimário do Cancioneiro da Ajuda (Víñez 1989), confunde numa única rima as parelhas ésse e êsse, éu e êu; e, apesar de distinguir ér e êr, introduz na primeira palavras rimantes que pertencem à segunda (sofrer, viver), e, à inversa, em êr outras que pertencem a ér (disser, fezer, mester, qualquer, quiser, segrer).

9 Uma advertência sobre a representação gráfica das rimas: conforme o princípio geral do actual sistema ortográfico português, emprego acento agudo para é, ó abertos (/'E/, /'つ/), e acento circunflexo para $\hat{e}, \hat{o}$ fechados (/'e/, /'o/). Como todas as rimas são tónicas pela sua mesma natureza, estes acentos gráficos usam-se aqui, pois, independentemente das normas de acentuação seguidas na transcrição habitual das correspondentes palavras rimantes (normas que são, no substancial, as mesmas da ortografia portuguesa actual). Assim, aparecerá acentuada graficamente uma rima (ôr, por exemplo) sem que as palavras em que tal rima entra devam levar acento (por exemplo, amor, lavor, pecador, senhor, etc.).

${ }^{10}$ Essas confusões de rimas mantêm-se igualmente na versão galega (Bertolucci 1992).

11 Assim acontece na citada cantiga de Dom Denis, à qual Tavani assigna a mesma fórmula rimática indicada por Nunes (Tavani 1967: 103, fórmula 88:1), que unicamente se daria nessa composição; na realidade, essa fórmula deve ser suprimida, e a cantiga em foco deve ser integrada na fórmula número 101 (]ababccb[), muito frequente. 
Ainda dous exemplos mais de interpretação rimática errada, esta vez da edição (magnífica, aliás) das Cantigas de Santa Maria por Mettmann.

Na CSM 423 Mettmann, depois de oferecer a fórmula rimática (que, de acordo com o sistema por ele seguido -o qual inicia pelas rimas do refrão-, é ]AAbccb[, equivalente portanto ao esquema indicado abaixo ]abba $C C[$ ), adverte: "En la primera estrofa la rima $c$ es igual a $A$ " (Mettmann 1989: 351, nota). Mas vejamos o começo da cantiga (refrão inicial e estrofe primeira):

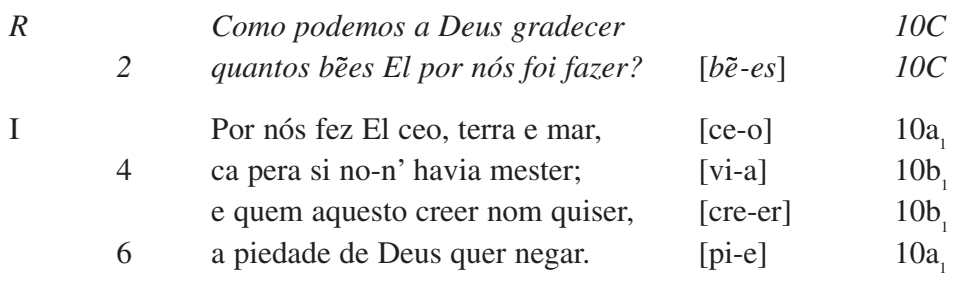

Temos aqui a parelha de rimas êr e ér, perfeitamente distintas e independentes: os dous versos do refrão rimam entre si em $\hat{e} r$, por terem como palavras rimantes infinitivos da segunda conjugação (gradecer, fazer), enquanto os versos segundo e terceiro da primeira estrofe apresentam palavras rimantes (mester e quiser) que possuem rima em ér, com é aberto, e rimam entre si mas não com o refrão. Deste modo, a cantiga não apresenta uma irregular repetição de rimas na primeira estrofe, mas todas as estrofes possuem regularmente a mesma fórmula rimática: ]abbaCC[.

Um segundo exemplo. Para a CSM 427 Mettmann dá o seguinte esquema métricorimático (Mettmann 1989: 360): A8 B8 A8 B8 B4 / c10 c10 c12 b15 (iniciando pelo refrão, como sempre faz, o que equivaleria, no sistema que adopto, a este: 10a 10a 12a 15b $8 C 8 B 8 C 8 B 4 B$ ). Supõe, pois, que os versos 2 , 4 e 5 do refrão inicial possuem idêntica rima (]$B[)$, coincidente com a do último verso de cada estrofe (]b[). Mas vejamos o início da composição (refrão inicial e estrofe primeira):

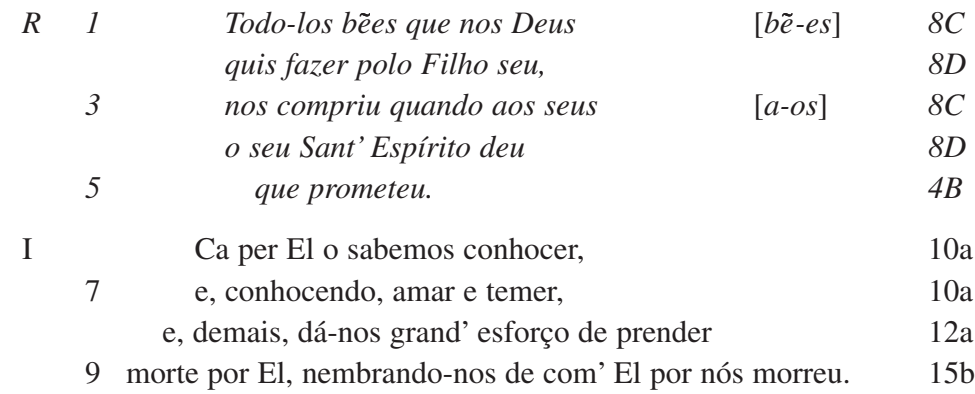


Havia na língua trovadoresca duas rimas $e u$, perfeitamente distintas entre si: uma com é de timbre aberto (éu) e outra com $\hat{e}$ fechado $(\hat{e} u)$. Pertenciam à primeira rima, com é aberto, entre outras palavras, os substantivos judeu, romeu e vergeu, os possessivos meu, teu, seu e a forma deu do verbo dar. À segunda, com $\hat{e}$ fechado, pertenciam as formas da terceira pessoa de singular do pretérito dos verbos da segunda conjugação (como morreu), e o adjectivo sandeu. Neste caso temos, pois, que rimam entre si os vv. 2 e 4 do refrão ( $s e u$ - deu), por uma parte, e, pela outra parte, rimam entre si o v. 5 do refrão e o v. 4 de cada estrofe (sempre com formas verbais em -êu: prometeu, morreu, recebeu, aprendeu, conteceu, encendeu, ensandeceu, leeu, cofondeu, entendeu, converteu, conquereu, naceu). Portanto, segundo o sistema seguido por Mettmann, o esquema métrico-rimático da presente cantiga seria este: A8 B8 A8 B8 C4 / d10 d10 d12 c15, equivalente ao que dou acima.

\section{Três factos filológicos}

Evitadas essas fontes de error na consideração das rimas, podemos dar um passo mais. Para não chegarmos a uma conclusão que pode ser errónea, convém termos em conta três factos de índole filológica que afectaram a diferença de timbre das vogais de grau médio; a saber:

1) que no sistema vocálico medieval se davam neutralizações fonológicas do timbre em determinadas circunstâncias;

2) que se deram já algumas mudanças de timbre ao longo dos 150 anos que compreende o período trovadoresco (aproximadamente 1200-1350);

3) que outras mudanças de timbre aconteceram depois da época trovadoresca.

\subsection{Neutralizações do timbre}

Em posição tónica o sistema fonológico vocálico da língua trovadoresca apresenta normalmente 7 fonemas (como ainda hoje na maior parte do território lingüístico, particularmente na Galiza e no Brasil). Podemos distribuí-los em três grupos, correspondentes às três localizações articulatórias fundamentais (central, anterior e posterior):

- Vogal central aberta /a/: representada graficamente por a: ave, canto.

- Série anterior (ou palatal): três fonemas vocálicos:

- Vogal anterior semi-aberta /ع/: representada graficamente por $e$ : bela, donzela, mel.

- Vogal anterior semi-fechada /e/: representada também por e: cedo, colherom, orelha.

- Vogal anterior fechada /i/: representada por $i$ : caminho, vi, vida. 
- Série posterior (ou velar): três fonemas vocálicos:

- Vogal posterior semi-aberta /っ/: representada por o: chora, porta.

- Vogal posterior semi-fechada /o/: representada também por $o$ : amores, esposa, valor.

- Vogal posterior fechada /u/: representada por $u$ : ajuda, lume, tu.

Ora, em determinados contextos fónicos, este sistema de 7 fonemas vocálicos em posição tónica vê-se reduzido a 5 fonemas, por neutralização da oposição entre as duas vogais de grau médio em cada uma das duas séries; isto é, entre / $/$ / e /e/ na série anterior, por uma parte, e, por outra, entre / / e /o/ na série posterior. Fica assim um único fonema vocálico de grau médio em cada série; a realização fónica desse único fonema resultante tende a ser fechada: anterior /e/, posterior /o/. Nesses casos, pois, o sistema do vocalismo tónico consta unicamente das seguintes 5 unidades: /a/, /e/, /i/, /o/, /u/.

Este sistema de 5 fonemas vocálicos em posição tónica ocorre nas seguintes circunstâncias (pelo menos):

1) Em sílaba travada pelo arquifonema nasal /N/; portanto, /'eN/ e /'oN/: rimas em, en-, etc.

2) Quando $e$ ou $o$ tónicos vão seguidos pela consoante palatal /3/: rimas eja, etc.

3) Quando $e$ ou $o$ tónicos vão seguidos pela nasal palatal /n/: rimas enha, etc.

4) Quando $e$ ou $o$ tónicos vão seguidos pela nasal velar / $/$ /: rimas em-e, etc.

5) Quando $e$ ou $o$ tónicos formam sílaba com a semivogal da mesma série.

Em todas essas circunstâncias as rimas parecem demonstrar -de acordo aliás com princípios de natureza fonológica bem conhecidos- que a língua literária propendia para a neutralização do grau de abertura, apesar de que em falas locais devia de perviver nalguns desses casos uma distinção de abertura em conformidade com a etimologia (pois ainda perdura hoje).

De facto, a maioria dessas rimas não suscitam dúvidas sobre a sua coincidência de timbre vocálico.

À luz dessa perspectiva fonológica devemos interpretar também algumas aparentes rimas de vogal aberta com vogal fechada.

Por exemplo, muitas das palavras rimantes em em possuíam etimologicamente $/ \varepsilon /$

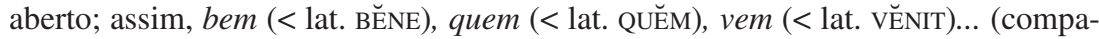
rem-se as correspondentes formas castelhanas ditongadas bien, quien, viene). Em várias delas a realização fonética tende ainda hoje à abertura, sobretudo nalguns 
falares mais conservadores, e provavelmente o mesmo acontecia já na época trovadoresca. Ora, entre essas palavras rimantes aparecem repetidamente algumas que possuíam por étimo /e/ fechado; por exemplo, o advérbio pronominal ém ( < lat. ĬNDE 'de ali') e a forma composta porém (< lat. PROINNDE 'portanto'), e os advérbios além (< lat. ILĽ̌NC 'de ali') e aquém (< lat. vg. ECCUM HINC 'de aqui'). Porém, o princípio de neutralização fonológica que vimos não nos permite concluir que existisse aí rima de vogal aberta com fechada.

\subsection{Mudanças de timbre dentro do período trovadoresco}

Nas rimas assomam indícios de que no decurso dos aproximadamente 150 anos (1200-1350) que abrange o período trovadoresco deram-se mudanças de timbre, que é preciso ter em conta para não deduzir daí que existe rima de vogal aberta com vogal fechada.

O exemplo que parece mais claro é o do nivelamento analógico que levou da forma dé a dê.

A forma de $3^{\mathrm{a}}$ pessoa de singular do presente de subjuntivo do verbo dar aparece em duas rimas diferentes: com vogal tónica aberta (dé) e com vogal tónica fechada $(d \hat{e})$.

A forma com tónica aberta (dé) é a etimológica: < lat. DĔT. Deve de corresponder, pois, a uma fase mais antiga que a forma dê, que é resultado do nivelamento analógico da vogal tónica com outras formas do mesmo tempo verbal e que perviveu na língua até os nossos dias.

Efectivamente, dé aparece em rima em textos do século XIII: nas CSM (2177.6), e em Joám Airas de Santiago (956.14). Ocorre também duas vezes em um trovador cuja fixação cronológica é ainda problemática: Martim Moxa (879.16; 886.9). A segunda destas composições (núm. 886), uma cantiga de amor, poderia datar também do século XIII, mas a outra (núm. 879), se é, como parece, uma tenção entre Martim Moxa e o conde Dom Pedro, deve ter sido composta no segundo quartel do século XIV, quando já parece ter-se estendido a forma dê. Teríamos então aqui uma confirmação da longevidade de Martim Moxa (que era um dos motivos de burla para Afonso Gômez na cantiga núm. 877 [= Tav 5,1], «Martim Moxa, a mià alma se perça» (Bd 886, $V$ [470]), de escárnio): já ancião na altura, Martim Moxa teria conservado em dé uma forma tradicional da sua língua de mocidade.

A forma secundária dê ocorre em rima em $\hat{e}$ em 3 composições dos tempos de Dom Denis (rei entre 1279 e 1325): em duas cantigas (573.12; 603.10) do próprio Dom Denis (1261-1325) e numa (862.16) de Dom Joám Meéndiz de Briteiros (aprox. $1270-1334 \ldots)$. 


\subsection{Mudanças de timbre depois da época trovadoresca}

É já bem conhecido que a língua trovadoresca mantinha o grau de abertura vocálica primitivo ou etimológico em determinados casos que depois a língua comum mudou por diversas causas, pelo menos em amplas zonas do território actual de língua galego-portuguesa. As rimas trovadorescas foram precisamente o instrumento que permitiu estabelecer com segurança esse estádio fonético conservador ${ }^{12}$. Enumero seguidamente os casos mais típicos, seguindo a ordem alfabética das rimas afectadas:

Ela, aquela. O pronome pessoal feminino ela (2285.61; 2360.10; 2369.109; e igualmente dela: $1451.14 ; 2148.11 ; 2360.9)$ e o demonstrativo aquela (daquela: 2305.60) aparecem rimando em êla (por exemplo, com formas de infinitivo acompanhadas de pronome enclítico, como prendê-la) e não em éla. Conservavam pois o /'e/ tónico fechado etimológico (como ainda hoje em alguns falares): ela $<$ lat. ILLLAM.

Esta, essa. Os demonstrativos esta (e aquesta) e essa mantinham o ê /e/ tónico etimológico (como ainda agora na Galiza): esta $<$ lat. ISTAM, essa $<$ lat. ĬPSAM ${ }^{13}$. O demonstrativo essa rima, por exemplo, com abadessa $<$ lat. ABBAŤ́SSAM. A par da rima êsta existe a correspondente rima com tónica aberta ésta, com palavras rimantes como festa ou sesta: o demonstrativo (aqu)esta não ocorre nunca nestoutra série.

$\boldsymbol{E u}, \boldsymbol{m e u}, \mathbf{t e u}, \mathbf{s e u}$. O pronome pessoal eu e os possessivos meu, teu, seu aparecem na poesia trovadoresca rimando entre si e com outras palavras que possuíam $e$ aberto etimológico, mas nunca com as formas em -eu de P3 do pret. perf. dos verbos em -er. Conservavam, pois, o é tónico aberto etimológico: $e u<$ lat. $\breve{\text { GO }}$ (cfr. cast. yo), meu < lat. MĔUM (cfr. cast. mio). As formas teu e seu, secundárias (formadas analogicamente sobre $m e u$, a partir das etimológicas tou < lat. TưUM, sou $<$ lat. SŬUM), incorporaram-se desde o seu nascimento a essa mesma situação fonética ${ }^{14}$.

12 Já Lapa recolheu vários destes caracteres fonéticos da língua trovadoresca (Lapa 1981: 232 no apartado intitulado «A língua dos trovadores»).

13 Veja-se Maia (1986: 345-348), que adverte do valor indicativo das rimas aquesta com comesta, e essa com abadessa.

${ }^{14}$ Veja-se Lapa (1981: 232): "Palavras como eu, meu, teu, seu, deu< dedit, Deus, judeu e outras, correspondentes a $e$ aberto latino, soavam ainda como tal, não sendo correcta a rima com a $3 .^{\text {a }}$ pessoa do singular do pretérito perfeito dos verbos em er: perdeu, temeu". Ademais da forma analógica seu, também a forma etimológica $s o u$ (< lat. SưUM) 'seu' aparece em rima ou, em 4 passagens: 10.12; 2046.56; $2314.61 ; 2410.26$. 
Maior, melhor, meor, peior. As formas de comparativo maior, melhor (e milhor), meor, peior (e peor), documentadas em posição de rima muito freqüentemente, aparecem rimando sempre em ôr /'oR/ e não em ór /'oR/. O mesmo acontece com os plurais maiores, melhores, meores: rimam em ôres /'ores/ e não em óres /'ores/. Mantinham, pois, o ô tónico fechado /'o/ etimológico (conservado ainda hoje na pronúncia geral da Galiza): maior < lat. MAIŌREM, melhor / milhor < lat. MELIŌREM, meor < lat. MINŌREM, peior / peor < lat. PEIŌREM ${ }^{15}$.

Essa é também a situação do advérbio redor, que ocorre repetidamente em rima nas suas formas compostas arredor, derredor enredor, embora a sua etimologia seja discutida.

Adjectivos em -osa. Os adjectivos formados com o sufixo feminino -osa conservavam, como ainda hoje na Galiza e noutras partes, a vogal tónica fechada da etimologia (< lat. -ōSAM), como nas formas masculinas em -oso ${ }^{16}$. Deduz-se do facto de aparecerem em rima com esposa (< lat. SPŌNSAM), que manteve sempre até hoje a tónica fechada.

\section{Indícios de homofonia de timbre}

Vimos até aqui alguns casos que poderiam interpretar-se erroneamente como rimas de vogal aberta com fechada.

Dando agora um passo mais, para comprovarmos se o tratamento que os trovadores davam ao timbre das vogais de grau médio nas rimas era cuidadoso, pode ser clarificador observar dous tipos de indícios que só parecem explicar-se como consequência de um respeito escrupuloso à diferença de timbre vocálico nas combinações de rimas. São:

1) a ausência de algumas palavras rimantes, e,

2) a existência de parelhas de rimas que se distinguem unicamente pelo timbre.

15 Veja-se Lapa (1981: 232): “as terminações dos comparativos maior, melhor, meor, peor, eram fechadas, e muito naturalmente, pois provinham de um $o$ fechado latino. Ainda hoje, em galego, se diz melhôr, piôr, maôr. Sabe-se o motivo por que a vogal é actualmente aberta no português: a forma maôr evoluiu para moor e depois para mór, e as outras formas tomaram, por analogia, a vogal aberta".

16 Veja-se Lapa (1981: 232): "Também, pelo motivo que acabamos de expor, isto é, pela existência de um $o$ fechado em latim, os adjectivos terminados em -osa se liam ainda ôsa: fremôsa. Só no século XVI, devido a influências analógicas ou à metafonia, a vogal se tornou aberta". Veja-se também Ferreiro (1997: 158-159). 


\subsection{Ausência de algumas palavras rimantes}

Se analisamos a aparição de palavras rimantes, surpreende a ausência, em posição de rima, de alguns vocábulos muito frequentes na língua. Nalguns casos trata-se de vocábulos com uma estrutura fonética particular; a sua ausência em rima explicase porque não existiam na língua outros vocábulos que posuíssem a mesma estrutura fonética. Mas em certos casos tal ausência parece dever-se unicamente a que era difícil achar no idioma palavras que tivessem o mesmo timbre vocálico aberto ou fechado, pois existem rimas com timbre vocálico diferente.

Fixemo-nos em dous casos: cego e velho (com as respectivas flexões de género e número). Estes vocábulos possuíam, como ainda hoje, vogal tónica aberta. Na poesia trovadoresca ocorrem as correspondentes rimas com timbre fechado (êgo, êlho), mas aí não foram incluídas, e parece lógico concluir que tal ausência se deve a que a diferença do timbre era obstáculo determinante.

O adjectivo (ou substantivo) cego aparece mais de 40 vezes na poesia trovadoresca (e a este número ainda poderíamos acrescentar as ocorrências rizotónicas do verbo cegar, que são 9). Aparece a rima êgo /'ego/, com as duas palavras rimantes comego pron. e Galego antrop. m. Mas nunca o vocábulo cego, que exigiria uma rima égo. Esta ausência torna-se ainda mais notável nas CSM, visto que alguns milagres têm como protagonistas pessoas cegas. (Poderiam rimar com as formas rizotónicas do verbo negar, mas não resultaria fácil inserir tais formas num relato).

O mesmo acontece com velho, que, nas suas quatro variantes flexivas, ocorre mais de cem vezes na poesia trovadoresca. Mas nunca em rima. Aparecem quatro rimas em elh-:

êlha l'eאa/: aparelha $\mathrm{P} 3$ pres., orelha s.f., ovelha s.f., parelha s.f., semelha ${ }_{1}$ s.f., semelha ${ }_{2}$ P3 pres., sortelha s.f., Telha antrop.f., vermelha adj. f.

êlhas /'eKas/: orelhas s.f.pl., semelhas s.f.pl., sobrancelhas e sobrencelhas s.f.pl.

êlho /'eאo/: anelho adj., botelho s.m., Coelho antrop. m., cõelho s.m., concelho s.m., conselho s.m., espelho s.m., folhelho s.m., golpelho s.m., sedelho (?) s.m., semelho $\mathrm{P} 1$ pres., trebelho s.m., vencelho s.m., vermelho adj., zarelho s.m.

êlhos l'eKos/: cõelhos s.m., conselhos s.m., trebelhos s.m.

Resulta, pois, significativa, neste grupo de quatro rimas em elh-, a ausência das correspondentes formas do adjectivo velho: tratando-se de um vocábulo frequente já na língua trovadoresca, parece evidente que a sua ausência em posição de rima se deve unicamente ao timbre aberto da sua vogal tónica.

Portanto, um indício que vem a confirmar a resistência dos trovadores a misturar em rima as vogais abertas com as fechadas. 
Algo parecido poderíamos dizer do adjectivo ledo, embora ocorra uma vez em rima na forma masculina, como logo veremos: existe assim uma rima édo, mas não éda, édos, édas. Sim, pelo contrário, a fechada êda /'eda/, com as palavras rimantes queda adj. f. e segreda s.f. O grau fechado da vogal tónica ê /'e/ desta rima deduzse da etimologia das duas palavras rimantes, que tem em ambos os casos $\overline{\mathrm{E}}$ longo na penúltima sílaba: queda adj. f. < lat. QUIĒTAM '='; segreda s.f. < lat. ecl. SECRĒTAM s.f. '='. Embora o número de palavras rimantes seja tão reduzido, podemos notar não só a ausência, entre elas, da forma adjectival feminina leda, mas a inexistência, propriamente falando, de uma rima éda: um indício mais de que os trovadores evitavam a mistura de palavras rimantes com diferente timbre vocálico.

\subsection{Parelhas de rimas}

Ocorrem na poesia trovadoresca as seguintes parelhas de rimas que se distinguem unicamente pelo timbre das suas vogais tónicas:

\begin{tabular}{|c|c|}
\hline é l'e/, ê l'e/ & és /'es/, ês /'es/ \\
\hline édes /'edes/, êdes /'edes/ & ésse /'ese/, êsse l'ese/ \\
\hline édo l'cdo/, êdo /'edo/ & éssem /'esen/, êssem l'esen/ \\
\hline él /’el/, êl /'el/ & ésta /'esta/, êsta l'esta/ \\
\hline éla /'ela/, êla /'ela/ & éstes /'Estes/, êstes /'estes/ \\
\hline élo /'elo/, êlo /'elo/ & éte l'cte/, ête l'ete/ \\
\hline émos l'emos/, êmos /'emos/ & éu /'ew/, êu /'ew/ \\
\hline éo /'Eo/, êo /'eo/ & óme l'ome/, ôme l'ome/ \\
\hline ér l'eR/, êr l'eR/ & ór /'OR/, ôr /'OR/ \\
\hline éra /'era/, êra l'era/ & óra l'ora/, ôra /'orsa/ \\
\hline éram l'eran/, êram /'eran/ & óres l'ores/, ôres l'ores/ \\
\hline
\end{tabular}

Ora, a análise das palavras rimantes nesses pares de rimas permite observar com que cuidado os trovadores mantinham a homofonia do timbre vocálico. Na maioria dos casos a homofonia do timbre é segura e não precisa de comentários. Porém, como nalguns casos podem surgir dúvidas sobre a regularidade do timbre, apresento esses casos seguidamente, acompanhados de um breve comentário.

\section{édo /'Edo/, êdo /'edo/}

édo /'edo/: derredo adv., ledo adj.m., Ovedo top.

êdo /'edo/: Arnedo top., azedo s.m., cedo adv., dedo s.m., degredo s.m., medo s.m., Olmedo top., quedo adj.-adv., Toledo top., vedo s.m. 
Das palavras rimantes da rima êdo, a maioria possuíam etimologicamente $\hat{e}$ tónico fechado /e/: azedo < lat. ACĒTUM, cedo < lat. CĬTO, dedo < lat. DĬGITUM, quedo < lat. QUIĒTUM, topónimos em -edo (Arnedo, Olmedo) $<$ lat. -ĒTUM. Frente a esse conjunto maioritário, causa surpresa a presença de medo, que originariamente devia possuir é tónico aberto (< lat. MĔTUM; compare-se o cast. miedo, com ditongo /je/), tal como o apresenta ainda hoje em alguns falares mais conservadores do Leste da Galiza.

Perante estes factos, podemos sacar uma das duas conclusões seguintes: 1) ou a pronúncia na época trovadoresca era ainda a originária, com é tónico aberto, e portanto trata-se de um caso de rima de vogal aberta com vogal fechada; 2) ou já se dera na língua comum a mudança do timbre, de é aberto para $\hat{e}$ fechado, tal como a vemos hoje na maior parte do território lingüístico.

Contra a primeira hipótese existem vários indícios que levam a considerar mais fundada a segunda; a saber:

1) medo, apesar de ser vocábulo muito frequente na poesia trovadoresca (por exemplo, é, na rima êdo, a palavra rimante que ocorre mais vezes), não aparece na rima édo. Teria algo de petitio principii objectar que esta rima édo ocorre unicamente uma vez em toda a poesia trovadoresca, e que portanto a ausência de medo aí não é significativa; antes ao contrário, visto o elevado número de ocorrências de medo, deveremos mais bem concluir que a sua ausência se deve à diferença de timbre vocálico, e que a escassa frequência da rima édo se deve precisamente tanto ao escasso número de palavras com essa rima existentes na língua medieval, como, com excepção de ledo, à sua escassa vitalidade.

2) medo aparece rimando com palavras que tinham ê tónico fechado (como azedo, cedo, dedo ou quedo) em 10 trovadores diferentes (vários deles do século XIII). Eis uma perspectiva das cantigas e autores em que ocorre a rima $\hat{e} d o$ :

494 (Afonso X): 37 medo s.m., 38 vedo s.m.

655 (Paai Soárez de Taveiroos): 8 cedo adv., 10 medo s.m.

832 (Pero da Ponte): 8 medo s.m., 9 cedo adv.

921 (Pero Gonçálvez de Portocarreiro): 3 cedo adv., 5 medo s.m.

937 (Pae de Cana): 5R medo s.m., 6R cedo adv.

969 (Joám Airas de Santiago): 15 quedo adj. m., 17 medo s.m.

1146 (Joám Servando): 7 cedo adv., 9 medo s.m.

1276 (Lourenço): 2 cedo adv., 3 medo s.m.

1329 (Estevam da Guarda): 8 cedo adv., 11 medo s.m., 14 dedo s.m.

1389 (Nuno Fernández Torneol): 3 Toledo top., 4 Olmedo top. 
1440 (Joám Servando): 15 Toledo top., 17 degredo s.m., 19 cedo adv., 21 vedo s.m. 1476 (Joám Baveca): 22 cedo adv., 25 quedo adj. m., 28 medo s.m.

1551 (Gil Pêrez Conde): 9 Olmedo top., 11 Toledo top.

2002 (CSM): 38 medo s.m., 40 Toledo top.

2009 (CSM): 88 medo s.m., 90 quedo adj. m.

2054 (CSM): 70 cedo adv., 71 medo s.m., 72 quedo adj. m.

2065 (CSM): 100 cedo adv., 101 Toledo top., 102 medo s.m.

2075 (CSM): 163 medo s.m., 164 cedo adv., 165 dedo s.m.

2083 (CSM): 50 cedo adv., 51 medo s.m., 52 quedo adj. m.

2091 (CSM): 48 medo s.m., 50 quedo adj. m.

2094 (CSM): 75 cedo adv., 78 medo s.m.

2105 (CSM): 14 medo s.m., 16 quedo adj. m., 18 cedo adv.

2115 (CSM): 192 cedo adv., 193 medo s.m.

2195 (CSM): 183 quedo adj. m., 184 medo s.m., 185 cedo adv., 188 degredo s.m.

2231 (CSM): 55 cedo adv., 56 medo s.m., 57 quedo adj. m.

2320 (CSM): 25 medo s.m., 27 cedo adv.

2369 (CSM): 113 dedo s.m., 114 medo s.m.

2386 (CSM): 15 cedo adv., 16 Toledo top., 17 Arnedo top.

2422 (CSM): 43 medo s.m., 44 azedo s.m.

Tal variedade de autores, assim como o facto de que alguns desses trovadores apresentam uma obra poética muito depurada, assim no aspecto lingüístico como na técnica literária, torna improvável a mistura de timbre aberto com fechado em rima. Parece, pois, mais fundado concluir que a metafonia da vogal tónica de medo era já comum na época trovadoresca.

\section{él /'el/, êl /'el/}

él l'el/: Abel antrop. m., anel s.m., batel s.m., bel adj. m., chapitel s.m., Cistel top., Conturbel top., cruel adj., Daniel antrop. m., donzel s.m., Emanuel antrop. m., fardel s.m., fiel s.m., fiel adj., froxel s.m., Gabriel antrop. m., Irrael top., Manuel antrop. m., mel s.m., Miguel antrop. m., Misael antrop. m., novel adj., pichel s.m., Raquel antrop. f., Samuel antrop. m., tropel s.m.

êl l'el/: daquel contr. de de + aquel demonstr. m., Reinel antrop. m.

Os adjectivos cruel (< lat. CRŪDĒLEM) e fiel (< lat. FĪDĒLEM) apresentavam já l'el tónico, como hoje, contrariamente à etimologia, qualquer que seja a explicação que deva dar-se a essa modificação. 
Para a terminação - el do antropónimo Reinel seria mais bem de esperar é tónico aberto /' $\varepsilon /$, em linha com os vários nomes de origem hebraica terminados em él (alguns citados na rima él, mas há ainda outros; por exemplo, Isabel, Ismael, Rafael), e até com a tendência fonológica geral induzida pelo /L/ implosivo (que parece ser a causa de que o resultado da vogal tónica de cruel e fiel fosse aberto, e não fechado como lhes corresponderia pelo étimo latino). Como para a outra palavra rimante (o demonstrativo daquel), não podemos supor senão /'e/, poderíamos ter aqui um caso de rima de vogal aberta /' $\varepsilon /$ com vogal fechada /'e/. Porém, parece seguro que se trata de um nome estrangeiro, provavelmente de origem galoromânica (fr. Reiner, com as variantes Rainer, Reinier, Rainier), e é compreensível que a adaptação galego-portuguesa conservasse a tónica fechada da língua original.

\section{éla /'ela/, êla /'ela/}

éla /'ela/: alcavela s.f., almocela s.f., ancela s.f., bela adj. f., Biringela antrop.f., cadela s.f., capela s.f., Castela top., caudela $\mathrm{P} 3$ pres., cela s.f., Compostela top., donzela s.f., escudela s.f., Estela top., fivela s.f., gonela s.f., mazela s.f., mesela s.f., mesela ${ }_{2}$ adj. f., morcela s.f., pastorela s.f., poncela s.f., revela $\mathrm{P} 3$ pres., sela s.f., Sousela top., stella s.f.lat., Todela top. e Tudela top., Varela antrop.m., vela P3 pres., Vela antrop.m.

êla l'ela/: camela s.f., daquela contr. de de + aquela, ela pron. pess., estrela s.f., mesela adj., querela s.f., e várias ocorrências de infinitivo com pron. encl. (movêla, põê-la, prendê-la, etc.).

Em alcavela, que procede do ár. al-qabîla, esperaríamos /e/ tónico fechado, e isto é o que parece confirmar a forma castelhana alcavera, sem ditongo tónico. Mas é possível que sobre a forma primitiva *alcavêla tenha agido o influxo do sufixo -ela

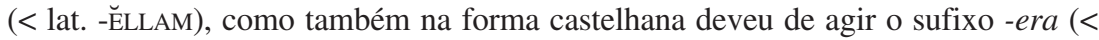
lat. -ARIAM) mais que a tendência meramente fonética à dissimilação -l-l- > -l-r-.

\section{éo /'عo/, êo /'eo/}

éo l'Eo/: aqué o = aqué adv. +o art., ceo s.m., hebre'o = hebreu s.m. +o pron. pess., veo s.m.

êo l'eo/: avangeo s.m., baraceo s.m., candeo s.m., creo P1 pres., esteo s.m., feo adj.m., receo $\mathrm{P} 1$ pres.

Das três palavras rimantes que ocorrem na CSM 75 (avangeo, creo, receo), somente creo aparece também nas cantigas profanas, mas isto parece suficiente para podermos assegurar o timbre fechado do e tónico. As duas formas verbais creo e receo tinham $\hat{e}$ fechado etimológico: creo < lat. CRĒDO, receo < prefixo re- + lat. CĒLO; esse $\hat{e}$ fechado conservou-se assim até hoje na maior parte dos territórios lusófonos, particularmente na Galiza e no Brasil: creio, receio. 
A outra palavra rimante dessa cantiga 2075, avangeo mostra uma evolução algo irregular, semiculta, do lat. EVANGĚLIUM (cfr. it. (e)vangelo); apesar de que em latim o -E- tónico era breve (e, portanto, devia dar é aberto, e assim se conserva no it. (e)vangelo), em avangeo, como se vê pelas outras duas palavras que com ela rimam, o $\hat{e}$ tónico devia de ser fechado, seguramente por influxo metafónico do -o final; a forma comum da língua actual, evangelho, de evolução mais regular mas quiçá também semicultismo, apresenta igualmente ê tónico fechado, aqui talvez por efeito conjunto da metafonia e da palatal seguinte $/ \delta /$. De qualquer modo, as restantes palavras rimantes desta rima, que a través de creo se ligam todas entre si, confirmam o grau fechado da vogal tónica de avangeo.

\section{és /'Es/, ês /'es/}

és l'es/: serventés s.m.pl. [provençal], vés s.m.pl. [provençal].

ês /'es/: alfrês s.m., aprês P3 perf., batarês s., borgês s.m., burgês s.m., cortês adj., emprês $\mathrm{P} 3$ perf., francês adj., marquês s.m., medês indef., mês s.m., montês adj., pês $\mathrm{P} 3$ pres. subj., prês $\mathrm{P} 3$ pret., três num., Salnês top., vês $\mathrm{P} 2$ pres.

A língua não oferecia outros vocábulos com rima és que a forma de $\mathrm{P} 2$ do verbo seer: és. Esta escassez será a causa de que tal rima és ocorra somente uma vez (e ainda, para isso, dando por suposto que seja correcta a nova leitura que proponho para a correspondente passagem da cant. 1431: dous vocábulos provençais, serventés e vés, ambos substantivos em plural, usados pelo trovador Picandom na sua tenção com Dom Joám Soárez Coelho).

\section{éte /'cte/, ête /'ete/}

éte l'cte/: mete $\mathrm{P} 3$ pres., sete num., topete s.m.

ête l'ete/: abete s.m., capeirete s.m., genete s.m., joguete s.m., Mafomete antrop. $\mathrm{m}$., mete $\mathrm{P} 3$ pres., promete $\mathrm{P} 3$ pres., remete $\mathrm{P} 3$ pres.

É duvidosa a existência desta parelha de rimas. O timbre aberto da vogal tónica da rima éte parece deduzirse-se sobretudo de sete < lat. SӖPTEM (cfr. cast. siete), e em menor medida de topete $<$ fr. ant. topet, hoje toupet (donde procedem o moderno cast. tupé e o al. Toupet). Mas a forma verbal mete ocorre também na rima ête (em passagem algo insegura, mas de qualquer modo a rima ête aparece também nos compostos promete e remete); originariamente teria /e/ tónico (< lat. M̆̌TTIT). Neste caso, para explicar esse duplo uso rimático não podemos lançar mão de diferenças cronológicas, pois os trovadores que empregam tais formas procedem todos de meados do século XIII.

Deveremos supor que já começava a difundir-se a mudança de timbre que daria o resultado actual com $/ \varepsilon /$ ? Ou talvez não existe uma rima ête, e todas as palavras rimantes que atribuí a esta rima possuíam realmente / $/$ / tónico? Efectivamente, o 
/ع/ tónico resulta explicável tanto nos arabismos genete e Mafomete como no sufixo de origem galo-românica -ete; então teríamos que concluir que tanto em mete como nos seus compostos estava já firmemente assentada a abertura do timbre.

ór /'oR/, ôr /'OR/

ór /'כR/: conor[-/to] s.m., cor s.m., for[-/te] adj., mor[-/te] s.f.

ôr /'OR/: substantivos e adjectivos procedentes do lat. -ŌREM (acabador s.f., açor s.m., agoirador adj. m., aguardador s.f., ajudador adj. m. e f., etc.), comparativos (maior, melhor ou milhor, mÈor, peior ou peor), for P1 e P3 do fut. subj. dos verbos seer e ir, por prep., as formas adverbiais baseadas em redor (arredor, derredor, enredor), Alcor [O ] top., Almançor antrop. m., atambor s.m., Azamor top., Leonor antrop. f., etc.

Vimos atrás a cantiga «Assi me trax coitado», de Dom Denis. A falta de palavras terminadas em ór /’oR/ na língua trovadoresca (pois já antes ficou notado que os comparativos maior, melhor, pior conservavam, como ainda hoje na Galiza, o timbre etimológico fechado /'oR/: rimam em ôr) levou Dom Denis, para achar rimas com o provençalismo cor, a lançar mão do artificioso expediente de dividir vocábulos em fim de verso e poder assim usar como rima alguma das suas sílabas internas. Mas claro está que lhe teria sido fácil encontrar muitas palavras rimantes em or se a homofonia do timbre vocálico não fosse uma condição considerada determinante.

\section{Fenómenos de analogia e metafonia}

Analisaremos a seguir alguns outros casos de rimas que poderiam suscitar dúvidas a respeito da homofonia do timbre, nos quais estão implicados fenómenos de modificação diacrónica do timbre vocálico por analogia ou metafonia.

Formas rizotónicas de verbos em -ecer. Observemos as rimas seguintes: nalgumas aparecem formas rizotónicas de verbos terminados em -ecer rimando com substantivos abstractos como sandece e velhece que, pelo seu sufixo, exigem $\hat{e}$ tónico:

êce l'etse/: acaece $\mathrm{P} 3$ pres., agravece $\mathrm{P} 3$ pres., aparece $\mathrm{P} 3$ pres., avorrece $\mathrm{P} 3$ pres., contece $\mathrm{P} 3$ pres., crece $\mathrm{P} 3$ pres., dece $\mathrm{P} 3$ pres., escrarece $\mathrm{P} 3$ pres., escurece $\mathrm{P} 3$ pres., esmorece $\mathrm{P} 3$ pres., esprandece $\mathrm{P} 3$ pres., estremece $\mathrm{P} 3$ pres., falece $\mathrm{P} 3$ pres., grãadece $\mathrm{P} 3$ pres., gradece $\mathrm{P} 3$ pres., guarece $\mathrm{P} 3$ pres., mancebece s.f., mece $\mathrm{P} 3$ pres., merece $\mathrm{P} 3$ pres., nodrece $\mathrm{P} 3$ pres., padece $\mathrm{P} 3$ pres., parece $\mathrm{P} 3$ pres., perece $\mathrm{P} 3$ pres., perte)ece $\mathrm{P} 3$ pres., rafece adj., recrece $\mathrm{P} 3$ pres., sandece s.f., velhece s.f.

êcem /'etsen/: gradecem P6 pres., merecem P6 pres. 
êces l'etses/: avorreces $\mathrm{P} 2$ pres., couseces $\mathrm{P} 2$ pres., escaeces $\mathrm{P} 2$ pres., escrareces $\mathrm{P} 2$ pres., esterreces $\mathrm{P} 2$ pres., faleces $\mathrm{P} 2$ pres., grãadeces s.f.pl., mereces $\mathrm{P} 2$ pres., padeces $\mathrm{P} 2$ pres., pareces $\mathrm{P} 2$ pres., rafeces adj. pl., sandeces s.f.pl.

êscas /'eskas/: crescas antrop. m. (ou s.f.pl. em função interjectiva?), empeescas P2 pres. subj.

êsco /'esko/: padesco $\mathrm{P} 1$ pres., paresco $\mathrm{P} 1$ pres.

Estas rimas, especialmente êce / etse/, êcem /'etsen/ e êces /'etses/, parecem indicar que em todas as formas rizotónicas dos verbos constituídos mediante os sufixos incoativos latinos -ĒSCĚRE, -ǏSCĚRE > -ecer a língua trovadoresca conservava ainda a pronúncia etimológica com ê tónico fechado /'e/: -ĒsČ́T > - êce, etc. É sabido que a pronúncia actual com é tónico aberto /' $\varepsilon /$ nalgumas dessas formas é fenómeno secundário, devido a influxos de natureza analógica.

Rima opem. Pode duvidar-se sobre o timbre do o tónico da rima opem. Com efeito, as duas palavras rimantes (opem e hisopem) não nos deixam sair de dúvidas; mas parecem existir mais razões em favor da pronúncia com $o$ aberto /’o/ em ambas.

Da forma latina opem, acusativo singular de ops / opis, deveremos esperar $o$ aberto, não tanto porque o vocábulo tinha em latim $o$ breve (isto é, ŏ) mas sobretudo porque na pronúncia romance de palavras latinas é comum a tendência à abertura do vocalismo tónico.

A outra palavra rimante, a forma verbal hisopem, pareceria opor-se a uma pronúncia com $o$ aberto, pois procede em última instância do lat. HYSSŌPUS / HYSSŌPI s.m. 'hissopo (erva: Hyssopus officinalis)', que tinha o tónico longo (isto é, ō, o qual, como de regra, devia resultar fechado em romance), confirmado pelo étimo grego

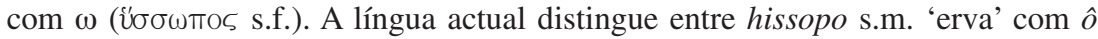
tónico fechado /'o/ e hissope s.m. 'aspersório' com ó tónico aberto /' o/; esta segunda forma parece ter origem galo-românica (provavelmente do fr. ant. hys(s)ope, hoje hysope; em provençal medieval documenta-se isop), e dela procede evidentemente o actual verbo hissopar 'aspergir com hissope', que achamos aqui em rima. Hoje este verbo hissopar apresenta ó aberto /'o/ nas formas rizotónicas dos presentes de indicativo e de subjuntivo (1 hissopo, 2 hissopas, 3 hissopa, 6 hissopam; 1 hissope, 2 hissopes, 3 hissope, 6 hissopem, forma esta que é a da presente rima); a abertura do ó na cantiga em foco indicaria que o substantivo de que deriva o verbo, isto é his(s)ope 'aspersório', antigo galicismo litúrgico, tinha já na época medieval $o$ aberto /'o/17.

17 Acerca da grafia, a hoje comum é com -ss-/s/, de acordo com o étimo greco-latino, mas na época medieval parece ter sido geral a pronúncia com /z/, e a correspondente grafia com - $s$ - simples, que já aparece em latim tardio. 
Rima ôsto. A rima ôsto /'osto/ apresenta as seguintes palavras rimantes: agosto s.m., aposto adj.m., deosto s.m., desaposto adj.m., posto part.m.

O timbre fechado da vogal tónica desta rima deduz-se da palavra rimante agosto s.m. < lat. AUGŬSTUM. Parece, pois, que era já habitual a metafonia em posto e nos seus compostos aposto e desaposto, que tiveram originariamente $o$ aberto (cfr. cast. puesto).

\section{Outros problemas}

Rima êem. A rima êem /'een/ apresenta estas 3 palavras rimantes: creem P6 pres., teem $\mathrm{P} 6$ pres., veem $\mathrm{P} 6$ pres.

Etimologicamente, as formas creem e veem tinham ê tónico fechado ( $<$ lat. CRĒDUNT; lat. VIDENT), e assim o tiveram sempre, mas teem (< lat. TĚNENT) devia ter é tónico aberto /' $\varepsilon /$ (cfr. cast. tienen). Se não queremos admitir rima imperfeita, temos que supor que na $3^{\mathrm{a}}$ pess. plur. teem a vogal tónica se tinha fechado quer por efeito da anterior nasalidade interior (aqui já desaparecida) na forma originária tẽem, quer por influxo analógico doutras formas do presente (assim, tenho, temos), nas quais, por efeito de diversos factores fonéticos, o resultado fora $\hat{e}$ fechado /'e/.

Que a nasalidade etimológica em posição interior de tẽem já desaparecera neste caso (tẽem > teem), demonstra-o a rima com creem e veem, que nunca tiveram nasalidade interior, e confirma-o a grafia do ms. (dado este que por si só não pode considerar-se decisivo, porém, pois é bem sabido que em qualquer texto medieval se dão casos de falta do til por mero descuido do amanuense).

Poderíamos perguntar-nos se esta rima êem /'een/ não deveria ser interpretada como êm, monossilábica e oxítona (fonologicamente /'eN/), sendo eem apenas uma grafia conservadora fictícia (como conjecturo que acontecia na CSM $282 \mathrm{com}$ a rima $\hat{e}$ ). Mas neste caso parece que há que responder negativamente a tal hipótese: entre outras dificuldades, toda a cantiga em foco (CSM 340) consta exclusivamente de rimas graves; isto parece querer dizer que, não tanto por regularidade poética quanto por necessidade de acomodação do texto à melodia, também -eem tem que ser paroxítona, e portanto bissilábica. A verdade, porém, é que, se, pelo contrário, se puder confirmar que na realidade se trata da rima êm /'eN/, monossilábica e oxítona, desapareceriam ambos os problemas que acabamos de comentar: o da diferença de abertura na vogal tónica e o da ausência de nasalidade interior na forma teem.

Rimas óa, óo, óos. A rima óa l' ’a/ ocorre com 3 formas da P3 do perf. da 1ª conjug. $+a$ pron. pess. f. enclítico: alçó- $a$, comungó- $a$, deitó- $a$. 
À vista das palavras rimantes (todas elas formas verbais de $\mathrm{P} 3$ do perf. de verbos da primeira conjugação com pronome pessoal enclítico: alçó-a, comungó-a, deitóa) poderia duvidar-se de qual era nesta rima o grau de abertura da vogal tónica - $o$, procedente de -ou (< lat. vulg. *-AUT < lat. cláss. -ĀVIT). Que era aberta /' o/, e não fechada /'o/, parece deduzir-se do confronto com as rimas óos e óo conjuntamente, visto que aí aparecem como palavras rimantes, ao lado de formas verbais similares às da rima que agora nos ocupa, vocábulos a que etimologicamente corresponde ó aberto /'o/, como avoo(s) (< lat. AVIŎLUM, AVIŎLOS; cfr. castelhano abue$l o(s))$ e doo ( < lat. DŎLUM; cfr. cast. duelo):

óo /’’o/: avoo s.m., desseinó-o P3 perf. + o pron. enclít., doo s.m., enlinhó-o P3 perf. $+o$ pron. enclít., feijoo s.m., negó-o P3 perf. +o pron. enclít., soo adj.m.

óos l’’os/: avoos s.m., filhó-os $\mathrm{P} 3$ perf. + os pron., lançó-os $\mathrm{P} 3$ perf. + os pron.

\section{Conclusão}

A análise das rimas trovadorescas mostra que a homofonia de timbre vocálico era um princípio fundamental.

No entanto, como nalguns vocábulos a abertura vocálica mudou da língua medieval à moderna por causa de influxos metafónicos ou analógicos, há casos em que resulta algo incerto estabelecer qual era a pronúncia na época trovadoresca. Mas à vista do comportamento que os trovadores mostram a respeito da homofonia do timbre vocálico no artifício das rimas, parece que estamos legitimados para aplicar, em princípio, também a esses casos incertos o que se pode constatar no grande número de casos seguros: que a rima era sempre perfeita e nunca se dava combinação rimática de vogal aberta com fechada ${ }^{18}$.

É um princípio geral, que corresponde ao ideal dos trovadores, realizado sistematicamente, mas que talvez não exige excluirmos, como eventualidade extrema, a possibilidade de alguma rara excepção ${ }^{19}$.

\footnotetext{
18 Assim acontecia também na poesia trovadoresca provençal, mas não todos os trovadores acertavam a manter com segurança este critério, como nota Martín de Riquer: "El manejo de la rima es riguroso e implacable. Excusado decir que no pueden rimar palabras en las que la tónica es una $e$ u $o$ abierta con otras de $e$ u $o$ cerrada, incorrección en que caen algunos trovadores catalanes" (Riquer 1983: 39, vol. 1, núm. 27 da «Introducción a la lectura de los trovadores»).

19 De resto, cumpre ainda advertir que, se a minha análise é correcta, também nas rimas assoantes -das quais não me ocupei aqui- os trovadores mantiveram a homofonia do timbre vocálico: como na antiga poesia francesa, a assonância afectava unicamente o consonantismo (ou semiconsonantismo).
} 


\section{Apêndices}

\section{Apêndice 1: Lista das rimas iniciadas por $e$ e por $o$}

As rimas iniciadas por $e$ e por $o$ são, em ordem alfabética, estas:

1) Rimas iniciadas pela vogal $\boldsymbol{e}$ (que fonologicamente pode ser é /'e/ ou $\hat{e}$ /'e/ ou $e$ l'e/): é l'c/, ê l'el, êa l'ea/, ẽa l'ena/, êas l'eas/, ẽas l'enas/, êça l'etsa/, êce l'etse/, êcem /'etsen/, êces /'etses/, éco /' $\mathrm{kko} /$, êço /'etso/, êda l'eda/, êde /'ede/, édes /'edes/, êdes /'edes/, édo l'edo/, êdo /'edo/, édra l'edra/, êe l'ee/, êem /'een/, ées /'ees/, ẽes /'enes/, êgo /'ego/, égua l'egwa/, ei /'ej/, eiga /'ejga/, eira l'ejra/, eiras /'ejras/, eiro /'ejro/, eiros /'ejros/, eis /'ejs/, eita /'ejta/, eite /'ejte/, eito /'ejto/, eitos /'ejtos/, eivos I'ejvos/, eixe l'ej/e/, eixo /'ejJo/, eja l'eza/, ejas l'ezas/, ejo /'ezo/, él l'el/, êl l'el/, éla

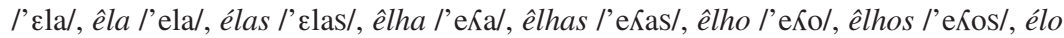
I'elo/, êlo /'elo/, êlos /'elos/, em /'en/, em-e l'eje/, émos /'emos/, êmos /'emos/, ênas /'enas/, ença /'entsa/, enda /'enda/, ende /'ende/, endo /'endo/, enha /'ena/, enho l'ejo/, êno /'eno/, ens /'ens/, enta l'enta/, entas /'entas/, ente l'ente/, entes l'entes/, ento /'ento/, entos /'entos/, éo l'co/, êo l'eo/, ẽo l'ejo/, ér /'eR/, êr /'eR/, éra l'era/, êra /'era/, éram /'eran/, êram /'eran/, érdes /'endes/, éres /'eres/, êrmos /'ermos/, érna /'erna/, érno l'erno/, éro l'ero/, érom l'eron/, êrom l'eron/, érra l'era/, êrro

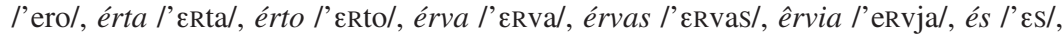
ês /'es/, êsa /'eza/, êscas /'eskas/, êsco l'esko/, êso /'ezo/, êssa l'esa/, ésse l'ese/, êsse /'ese/, éssem /'esen/, êssem /'esen/, ésses /'eses/, ésta l'esta/, êsta l'esta/, éste l'Este/, éstes /'estes/, êstes /'estes/, êta /'eta/, éte l'cte/, ête l'ete/, éu l'ew/, êu l'ew/, éus l'cws/, éva l'eva/, êz.l'edz/, êza l'edza/, êzas /'edzas/.

2) Rimas iniciadas pela vogal $o$ (que pode ser $o$ /'o/ ou $\hat{o} /$ /'o/ ou $o$ /'o/): óa /'oa/, õa /'ona/, ôas /'onas/, óbre l'obre/, óbres /'obres/, ôces /'otses/, ôda /'oda/, óde l'ode/, óe l'’e/, ões /'ones/, ógo /'ogo/, ôi /'oj/, ôira l'ojra/, ôiro /'ojro/, ôiros /'ojros/, ôita /'ojta/, ôitas /'ojtas/, ôito /'ojto/, ól l'ol/, ôlas /'olas/, óle l'ole/, ôlhos /'oKos/, ólo /'olo/, om /'on/, om-e l'one/, ôma /'oma/, omba l'onba/, óme l'ome/, ôme l'ome/, ómo l' $\mathrm{mmo} /$, onda /'onda/, ondas /'ondas/, onde l'onde/, ondo /'ondo/, ongo /'ongo/, onha l'ona/, ôno /'ono/, onta l'onta/, onte /'onte/, ontes /'ontes/, onto /'onto/, óo l'oo/, õo l'ojo/, óos l'oos/, ópem l'open/, ór l'on/, ôr /'oR/, óra l'ora/, ôra l'ora/, óram /'oran/, óre l'ore/, óres /'ores/, ôres /'ores/, óro /'oro/, órre l'ore/, órta l'onta/, órte l'orte/, órto l'oRto/, órtos l'oRtos/, ós l'os/, ôsa l'oza/, ôsas /'ozas/, ôsco l'osko/, ôso l'ozo/, ôsos /'ozos/, óssa l'osa/, ósso /'oso/, óste /'oste/, ôsto /'osto/, ôta l'ota/, ou l'ow/, oua l'owa/, ouca l'owka/, ouco /'owko/, ouço l'owtso/, oulhe l'owKe/, oume l'owme/, ouro /'owro/, ouros /'owros/, ous /'ows/, ousa /'owza/, ousas /'owzas/, ousse /'owse/, ouve l'owve/, óvo l'ovo/, ôxa l'oja/, óz, l'oDz/, ózes l'odzes/.

\section{Apêndice 2: Rimas com neutralização fonológica de timbre}

1) Em sílaba travada pelo arquifonema nasal /N/; portanto, /'eN/ e /'oN/.

Deste modo, não apresentam diferente grau de timbre vocálico as rimas seguintes: 
em l'en/, ença l'entsa/, enda l'enda/, ende /'ende/, endo /'endo/, ens l'ens/, enta l'enta/, entas /'entas/, ente l'ente/, entes /'entes/, ento /'ento/, entos /'entos/, om l'on/, omba l'onba/, onda l'onda/, ondas /'ondas/, onde /'onde/, ondo /'ondo/, ongo l'ongo/, onta /'onta/, onte l'onte/, ontes /'ontes/, onto /'onto/.

Assinalo a seguir, para cada uma destas rimas, as principais palavras rimantes:

em /ev/: além adv., alguém indef., almazém s.m., amém adv., aquém adv., argém s.m., avém $\mathrm{P} 3$ pres., Beleém top., bem ${ }_{1}$ s.m., bem 2 adv., brem s.m., Çocodevém (?) top., convém 1 s.m., convém 2 P3 pres., dem P6 pres. subj., desavém P3 pres., desdém s.m., destém $\mathrm{P} 3$ pres., detém $\mathrm{P} 3$ pres., ém adv., falimém s.m., feramém adv., gafém s.f., Jaém top., Jerusalém top., ligeiramém adv., mantém P3 pres., porém adv., quem $m_{1}$ relat., quem $m_{2}$ interr., rem r.f., rem $_{2}$ indef., Santarém top., sém s.m.,

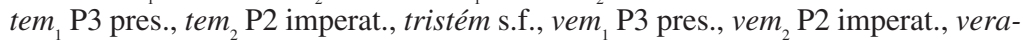
mém adv., veroyamen adv. [provençal].

ença l'entsa/: atrevença s.f. (e outros substantivos em -ença), mença P3 pres. subj., Olivença top., Proença top., sença $\mathrm{P} 3$ pres. subj., vença $\mathrm{P} 3$ pres. subj., etc.

enda l'enda/: aprenda $\mathrm{P} 3$ pres. subj., atenda $\mathrm{P} 1$ e $\mathrm{P} 3$ pres. subj., comenda, comen$d a_{2} \mathrm{P} 3$ pres., comprenda $\mathrm{P} 1$ pres. subj., contenda s.f., defenda $\mathrm{P} 1$ e $\mathrm{P} 3$ pres. subj., emenda ${ }_{1}$ s.f., emenda 23 pres., emprenda $\mathrm{P} 1$ pres. subj., encomenda s.f., entenda P1 e P3 pres. subj., fazenda s.f., leenda s.f., merenda s.f., oferenda s.f., Ousenda antrop. f., prebenda s.f., prenda P1 e P3 pres. subj., quejenda indef. f., renda s.f., tenda s.f., venda $a_{1}$ s.f., venda ${ }_{2} \mathrm{P} 3$ pres. subj.

ende l'ende/: alende adv., atende $\mathrm{P} 3$ pres., contende $\mathrm{P} 3$ pres., daquende adv., decende $\mathrm{P} 3$ pres., defende $\mathrm{P} 3$ pres., despende $\mathrm{P} 3$ pres., emende $\mathrm{P} 3$ pres. subj., ende adv., entende $\mathrm{P} 3$ pres., fende $\mathrm{P} 3$ pres., merende $\mathrm{P} 3$ pres. subj., porende adv., prende $\mathrm{P} 3$ pres., recende $\mathrm{P} 3$ pres., rende $\mathrm{P} 3$ pres., reprende $\mathrm{P} 3$ pres., revende $\mathrm{P} 3$ pres.

endo l'endo/: acomendo $\mathrm{P} 1$ pres., acorrendo (e muitas outras formas de gerúndio da $2^{\mathrm{a}}$ conjug.), aprendo $\mathrm{P} 1$ pres., comendo $\mathrm{P} 1$ pres., defendo $\mathrm{P} 1$ pres., enmendo $\mathrm{P} 1$ pres., entendo $\mathrm{P} 1$ pres., Meendo antrop. $\mathrm{m}$., rendo $\mathrm{P} 1$ pres., vendo $\mathrm{P} 1$ pres.

ens /'ens/: Cunctipotens adj. lat., Ourens' $=$ Ourense top. ${ }^{20}$

enta l'enta/: acrecenta P3 pres., ementa P3 pres., enmenta P3 pres., escaenta P3 pres., escarmenta $\mathrm{P} 3$ pres., genta adj. f., Muimenta top., oitaenta num., parenta s.f., quaraenta / quareenta num., senta P1 pres. subj., sergenta s.f., sessenta num., setaenta num., setenta num., tenta $\mathrm{P} 3$ pres., tormenta ${ }_{1}$ s.f., tormenta ${ }_{2} \mathrm{P} 3$ pres.

${ }^{20} \mathrm{Na}$ época trovadoresca a terminação - $n s$ /NS/ não formava ainda parte do sistema fonológico da língua: não existiam palavras terminadas em - $n s$, pelo menos na língua comum. No entanto, a aparição desta rima numa cantiga de Afonso x justifica-se pela conjunção de vários factores: 1) foi forçada pelo vocábulo latino Cunctipotens, tomado da liturgia; 2) para isso o autor teve que praticar no topónimo Ourense a apócope da vogal final, fenómeno este que era normal em castelhano mas anómalo em galego-português: isto explica-se num trovador de fala castelhana como o rei Afonso x; 3) ocorre numa cantiga de escárnio, onde a contravenção das normas podia ajudar a aumentar o carácter lúdico do poema. Note-se ademais a pronúncia oxítona da palavra latina, como acontece com outros latinismos em rima (Brutus, Colistanus, Moysi e triclinium, e igualmente nos grecismos Aioz e kyrieleison). 
entas /'entas/: quatrocentas num., quinhentas num., tormentas s.f., trezentas num.

ente /'ente/: abertamente adv. (e outros advérbios em -mente), arente s.m., argente s.m., Benavente top., caente adj., ciente s.m., Clemente [Sam ] antrop. m., contenente s.m., Crecente top., creente adj., Cremente antrop. m., dente s.m., desmente P3 pres., doente adj., emente adv., empossente (?) adj. (?), enment' $e=$ enmente $+e$ conj. copul., entendente part., gente s.f., maldizente part., mantenente adv., mantentent' $e=$ mantenente adv. $+e$ conj., mente $\mathrm{P} 3$ pres., mente s.f., negrigente adj., niente indef., obediente adj., omnipotente adj., ouriente s.m., parente s.m., presente adj., pungente adj., remordente s. (?), repente P3 pres., sente P3 pres., sergente s.m., serpente ablat. lat., servente s.m., te)ente adj., Vicente $[$ Sam $\sim$ antrop. $\mathrm{m}$.

entes l'entes/: ardentes part., creentes part., dentes s.m., descreentes part., doentes s.m., ferventes part., gentes s.f., maldizentes part., mentes s.f., obedientes adj., parentes s.m., presentes ${ }_{1}$ s.m., presentes ${ }_{2}$ adj., pungentes part., sergentes s.m., te)entes part.

ento /'ento/: apoderamento s.m. (e outros substantivos em -mento), arento s.m., Avento s.m., balorento adj., cento num., comprimento s.m., convento s.m., cousimento s.m., emento P1 pres., ongüento s.m., Sarmento antrop. m., tento s.m., vento s.m., etc.

entos /'entos/: acorrimentos s.m. (e outros substantivos em -mentos), duzentos num., medorentos adj. m. pl., oitocentos num., quinhentos num., trezentos num., ventos s.m., xermentos s.m., etc.

om l'on/: aguilhom s.m., algodom s.m. (e muitos outros substantivos, masculinos e femininos), bom adj., felom adj., nom adv., perdom $\mathrm{P} 3$ pres. subj., pom $\mathrm{P} 3$ pres., som $\mathrm{P} 6$ pres., etc.

omba l'onba/: comba adj.f., lomba s.f., Tomba top.

ondas /'ondas/: fondas adj.f.pl., ondas s.f.pl.

onde l'onde/: conde s.m., confonde $\mathrm{P} 3$ pres.

ondo /'ondo/: avondo indef., fondo ${ }_{1}$ s.m., fondo adj.m., redondo adj.m.

ongo /'ongo/: alongo $\mathrm{P} 1$ pres., Valongo top.

onta /'onta/: conta s.f., fronta s.f.

onte l'onte/: conte P1 pres. subj., fonte s.f., fronte s.f., monte s.m.

ontes /'ontes/: fontes s.f., montes s.m.

onto /'onto/: conto 1 s.m., conto 2 P1 pres., ponto s.m.

2) Quando $e$ ou $o$ tónicos vão seguidos pela consoante palatal /3/. Acontece isto nas rimas eja /'eza/, ejas /'ezas/, ejo /'ezo/:

eja /'e3a/: deseja P3 pres., egreja s.f. (com as variantes eigreja e igreja), enveja s.f., faroneja $\mathrm{P} 3$ pres., peleja ${ }_{1}$ s.f., peleja ${ }_{2} \mathrm{P} 3$ pres., rabeja $\mathrm{P} 1$ pres., seja $\mathrm{P} 1$ e $\mathrm{P} 3$ do pres. de subj., sobeja adj. f., veja $\mathrm{P} 1$ e P3 do pres. de subj., veja[-/mo-la] = vejamos $\mathrm{P} 4$ pres. subj. + la art. def.f. 
ejas l'ezas/: envejas s.f.pl., igrejas s.f.pl., sejas P2 pres. subj.

ejo /'ezo/: antejo s.m. 'entejo', desejo ${ }_{1}$ s.m., desejo ${ }_{2} \mathrm{P} 1$ pres., entejo s.m., mejo P1 pres., sejo $\mathrm{P} 1$ pres., sobejo adj., vedejo s.m. (castelhanismo) 'guedelha', vejo P1 pres.

3) Quando $e$ ou $o$ tónicos vão seguidos pela nasal palatal /n/. Assim, nas rimas enha /'ena/, enho /'ejo/, onha /'oja/:

enha l'ena/: Belenha top., berengenha s.f., desdenha P3 pres., detenha P3 pres. subj., emprenha $\mathrm{P} 3$ pres., tenha $\mathrm{P} 3$ pres. subj., venha $\mathrm{P} 3$ pres. subj.

enho /'ejo/: tenho $\mathrm{P} 1$ pres., venho $\mathrm{P} 1$ pres.

onha l'ona/: aponha P3 pres. de sub., besonha s.f., Bolonha top., çamponha s.f., Catalonha top., Colonha top., Gasconha top., menzonha s.f., Monçonha top., Onha top., Osonha top., ponha $\mathrm{P} 3$ pres. subj., risonha adj., Sansonha top., sonha P3 pres., Toronha top., vergonha s.f.

4) Quando $e$ ou $o$ tónicos vão seguidos pela nasal velar $/ \mathrm{y} /$. Isto acontece naquelas rimas em que $e$ e $o$ levam o til de nasalidade ${ }^{21}$ : ẽa /'ena/, ẽas /'ejas/, ẽes /'ejes/,

${ }^{21}$ Com respeito às vogais escritas com til de nasalidade em textos trovadorescos, parto de dous pressupostos metodológicos que não é agora momento de justificar em detalhe mas que, embora sejam simplesmente hipóteses de trabalho, considero mais coerentes com os dados da nossa história lingüística do que as teorias alternativas. 1) A primeira dessas duas hipóteses de trabalho é que todas as vogais da língua trovadoresca são fonologicamente orais: embora possam aparecer mais ou menos nasalizadas fonicamente por contacto com uma consoante nasal (explosiva ou implosiva), tal nasalização carece de relevância fonológica. De resto, essa é também a interpretação que penso deve dar-se à situação actual em todo o domínio da língua portuguesa, contrariamente à ideia -mais divulgada entre gramáticos e filólogos- de que existem vogais nasais em português -ideia provocada talvez mais que nada pela miragem do uso ortográfico do til de nasalidade sobre as letras vogais-: as supostas «vogais nasais» da língua moderna não são senão uma sucessão, no discurso, de duas unidades fonológicas: [vogal + o arquifonema consonântico nasal implosivo /N/]; vejam-se, por exemplo, os argumentos de Mattoso Câmara (1976: 36-37, 48-50, e 1977: 67-72, 82, 109-111) e de Morais Barbosa (1965: 91104) em favor desta interpretação fonológica. Esse par fonológico ocorre na língua moderna somente em posição pré-consonântica interior (por exemplo, vinde /'vinde/) ou em fim de vocábulo (fim l'fin/); portanto sempre em posição implosiva (embora na realidade muitos desses casos em fim de vocábulo se transformem no discurso, mercê à fonética sintáctica, em ocorrências em posição explosiva). O sistema fonológico medieval apresentava ademais o mesmo fenómeno também em posição intervocálica interior de vocábulo, onde se realizava como nasal velar [n] (a qual pervive ainda na pronúncia popular do artigo indefinido feminino ['una], geral não só na Galiza mas também popularmente no resto do território lingüístico). Portanto, mediante o til representa-se não uma vogal nasal mas uma vogal (oral) seguida do fonema consonântico nasal, que em posição intervocálica se realiza como velar [ᄁ]. 2) A segunda hipótese de trabalho é que, vista a estrutura silábica da língua, essa consoante nasal velar intervocálica $[\mathrm{y}]$ representada pelo til tinha de ser, na época medieval, um fonema consonântico em posição explosiva, isto é, que iniciava sílaba; portanto, formava sílaba com a vogal seguinte (como hoje em ['ũyã], ũa na grafia medieval), e não com aquela sobre a qual vai colocado o til. O sistema ortográfico resulta algo enganoso neste caso (para a situação fonológica medieval, mais ainda que para a actual): assim, o substantivo mão (hoje monossílabo: /'mawn/ na pronúncia luso-brasileira, e /'maN/ e /'maw/ e mesmo /'ma/ nos falares da Galiza) era bissílabo na época medieval, como mostra a métrica, e seria silabicamente /'ma-no/. 
ẽo /'ejo/, õa l'oja/, õas /'ojas/, ões /'ojes/, õo /'ojo/; e igualmente nas rimas que represento graficamente como em-e /'eje/, e om-e /'one/22.

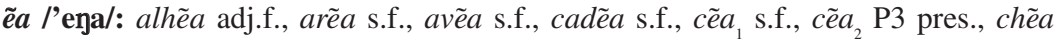
adj.f., cordovẽa s.f., estrẽa P3 pres., frẽa (?) P3 pres., Leirẽa top. 'Leiria', Lucẽa top. 'Lucena (Córdova)', pẽa s.f., Sẽa top., vẽa s.f.

ẽas /'eĐas/: amẽas s.f.pl., arẽas s.f.pl., cadẽas s.f.pl., pẽas s.f.pl., vẽas s.f.pl.

ẽes /'enes/: bẽes s.m., tẽes $\mathrm{P} 2$ pres., vẽes $\mathrm{P} 2$ pres.

ẽo /'eno/: alhẽo adj.m., avẽo P3 perf. do vrb. avñir, chẽo adj.m., fẽo s.m., quinzẽo num. ord. m., sẽo s.m., setẽo num. ord. m., Terrẽo [Mar ] top.m., vẽo P3 perf. do vrb. vñir.

õa l'ona/: abaldõa P3 pres., Ambrõa top., apregõa P3 pres., bõa adj., borõa s.f., corõa s.f., dõa s.f., galardõa $\mathrm{P} 3$ pres., infançõa s.f., ladrõa s.f., leõa s.f., Lisbõa

22 Nestas rimas em-e e om-e trata-se sempre de casos de - $e$ paragógico; isto, é, de palavras rimantes nas quais o arquifonema nasal $/ \mathrm{N} /$ em fim de vocábulo recebeu o acrescento de um -e paragógico, que mudou a estrutura silábica da rima. Adoptei essa grafia com $m$-e para conservar mais claramente a identificação visual com as palavras-base, terminadas em - $m$; mas a verdade é que fonologicamente essa grafia é inadequada e pode resultar enganosa. Se a minha interpretação fonológica é correcta, seria mais exacta uma representação gráfica mediante til (portanto, ẽe, õe); e não porque o til resulte fonologicamente apropriado para a língua medieval, mas porque assim ficaria claro que também estas duas rimas em-e e om-e pertencem, no que diz respeito ao tratamento da vogal tónica, à série das que representamos com til. Em coerência com estoutra série poderíamos pois adoptar a grafia ẽe e õe; seria o que nos veríamos obrigados a fazer se ocorressem como palavras rimantes não só vocábulos com - $e$ paragógico mas formas como cẽe, do verbo cẽar, ou sõe, do verbo sõar, que, segundo creio, no sistema fonológico medieval poderiam rimar com as que represento como em-e e om-e respectivamente. Seria ademais coerente com a representação gráfica da rima ẽes; a este respeito, não deixa de ser significativo que os três vocábulos rimantes em ẽes (bẽes s.m., e as formas verbais tẽes e vẽes) sejam os mesmos que achamos aqui, agora sem $-s$ final, rimando novamente entre si: bem-e, tem-e, vem-e. Os mss. das CSM ( $E$ 115, T 115, U 55) transcrevem -ene, e assim edita também Mettmann (bene, tene, vene); mas esta transcrição deve ser interpretada como uma tentativa, por parte dos escribas medievais, de representação aproximada e imperfeita da nasalidade velar [n]. Embora a nasalidade velar intervocálica fosse um fenómeno fonético muito freqüente tanto em fonética sintáctica (consoante nasal final de palavra /N/ + vogal inicial da palavra seguinte) como em fonética da palavra (representada habitualmente mediante o til sobre a vogal precedente, como fica explicado), o caso do -e paragógico deveu de produzir embaraço nos escribas a respeito da sua representação gráfica. A nasalidade final de vocábulo (o arquifone$\mathrm{ma} / \mathrm{N} /$ ) ante pausa ou ante palavra iniciada por vogal não se realizava como alveolar [n] mas como velar [n]; claro está que esta realização fonética não podia variar ao adir-se o $e$ paragógico, elemento ocasional que a consciência do falante interpreta claramente como eventual e que não modifica a preexistente conformação fonética da palavra afectada. Quando se trata doutras consoantes finais, como $-l$ ou $-r$, a representação gráfica do - $e$ paragógico não precisa de nenhum artifício especial: podemos escrever simplesmente, por exemplo, male, Portugale, dare, pecare, mare (vocábulos que ocorrem de facto em posição de rima na poesia trovadoresca). Mas no caso da nasal o assunto é diferente. Como a grafia ene resulta desorientadora porque sugere que se trata de realização alveolar [n] quando na realidade é velar [n], para evitar malentendidos julgo preferível assumir outro sistema de representação gráfica do fenómeno: poderia talvez adoptar-se a grafia - $m h$-, que se pode abonar em textos medievais e é também usada por alguns modernamente na Galiza para representar a pronúncia velar, habitual na fala da Galiza, do artigo indefinido feminino (umha, umhas, algumha, algumhas, nengmha, nengumhas); mas finalmente decido-me pelo uso do hífen pelas razões apontadas. 
e Lixbõa top., nõa s.f., padrõa s.f., Padrõa antrop.f. (?), perdõa P3 pres., pessõa s.f., razõa $\mathrm{P} 3$ pres., sõa ${ }_{1} \mathrm{P} 3$ pres., sõa ${ }_{2} \mathrm{P} 2$ imperat., varõa s.f.

õas l'ołas/: bõas adj., cochõas s.f., dõas s.f., infançõas s.f., pessõas s.f., varõas s.f.

ões l'ones/: plurais de substantivos terminados em -om, masculinos e femininos (alguns deles aumentativos): arções s.m., arlotões s.m., barões s.m., bastões s.m., beeições s.f., bolsões s.m., cabrões s.m., çapatões s.m., carvões s.m., etc.

õo /'oło/: bõo adj.m., sõo P1 pres., trõo s.m.

em-e l'ene/: três vocábulos terminados em -em mais -e paragógico: bem-e s.m., teme $\mathrm{P} 3$ pres., vem-e $\mathrm{P} 3$ pres.

om-e l'one/: vocábulos terminados em -om mais - e paragógico: Cantom-e antrop.m. (Pero Cantom-e), Gordom-e antrop.m. (Dom Palaio de Gordom-e), Leom-e top., Orzelhom-e top., Palaio de Gordom-e antrop.m., Pero Cantom-e antrop.m., sazom-e s.f., tapom-e s.m., vençom-e s.f.

5) Quando $e$ ou $o$ tónicos formam sílaba com a semivogal da mesma série; isto é, nos ditongos decrescentes ei e ou (mas não em éu, êu, nem provavelmente em ói, ôi). Portanto, todas as rimas iniciadas por ei e por ou apresentam um único timbre vocálico; são as seguintes: ei /'ej/, eiga /'ejga/, eira /' ejra/, eiras /'ejras/, eiro /'ejro/, eiros /'ejros/, eis /'ejs/, eita /'ejta/, eite /'ejte/, eito /'ejto/, eitos /'ejtos/, eivos /'ejvos/, eixe l'ej/e/, eixo /'ejJo/; ou l'ow/, oua /'owa/, ouca l'owka/, ouco /'owko/, ouço /'owtso/, oulhe l'owKe/, oume I' owme/, ouro /'owlo/, ouros /'owlos/, ous /'ows/, ousa l'owza/, ousas /'owzas/, ousse /'owse/, ouve /'owve/:

ei /'ej/: acabarei (e muitas outras formas de P1 fut.), acabei (e muitas outras formas de $\mathrm{P} 1$ perf.), Candarei top., dei $\mathrm{P} 1$ perf., hei $\mathrm{P} 1$ pres., lei s.f., mei pron. lat., rei s.m., sei $\mathrm{P} 1$ do pres., tornei $\mathrm{s.m}$. , etc.

eiga /'ejga/: manteiga s.f., meiga s.f., taleiga s.f., Veiga top.

eira /'ejra/: arteira adj. (e muitos outros adjectivos em -eira), azinheira s.f. (e muitos outros substantivos em -eira), cheira $\mathrm{P} 3$ pres., feira $\mathrm{P} 3$ pres. subj., queira ${ }_{1} \mathrm{P} 1$ pres. subj., queira ${ }_{2} \mathrm{P} 3$ pres. subj., etc.

eiras /'ejras/: arteiras adj. (e muitos outros adjectivos em -eiras), barreiras s.f. (e muitos outros substantivos em -eiras).

eiro /'ejro/: armeiro s.m. (e muitos outros substantivos em -eiro), arteiro adj. (e muitos outros adjectivos em -eiro), conqueiro $\mathrm{P} 1$ pres., fazfeiro s.m., refeiro $\mathrm{P} 1$ pres.

eiros /'ejros/: arteiros adj. (e muitos outros adjectivos em -eiros), carneiros s.m. (e muitos outros substantivos em -eiros).

eis l'ejs/: leis s.f., reis s.m., seis num. card.

eita /'ejta/: asseita P2 imperat., dereita adj., encolheita part., escolheita part., espreita $\mathrm{P} 3$ pres., feita part., seita s.f., sospeita s.f., tolheita part., treita part.

eite l'ejte/: azeite s.m., arreite adj., deite P3 pres. subj., espeite P3 pres. subj., leite s.m., preit' $e=$ preito s.m. $+e$ conj., tragazeite s.m. 
eito /'ejto/: afeito adv., Beeito antrop. m., be)eito adj., congeito s.m., contreito part., deito $\mathrm{P} 1$ pres., deleito s.m., dereito ${ }_{1}$ s.m., dereito ${ }_{2}$ adj., desfeito part., despeito s.m., eito $[a \sim]$ loc. adv., encolheito part., endeito $\mathrm{P} 1$ pres., escolheito part., escorreito part., estreito ${ }_{1}$ s.m., estreito ${ }_{2}$ adj., feeito s.m., feito ${ }_{1}$ s.m., feito ${ }_{2}$ part., jeito s.m., leito s.m., maltreito part., odeito part., peito 1 s.m., peito 'paga', preito s.m., proveito s.m., retreito part., sospeito $\mathrm{P} 1$ pres., teito s.m., tolheito part., trasgeito s.m.

eitos /'ejtos/: contreitos adj., desafeitos adj., feitos ${ }_{1}$ s.m., feitos ${ }_{2}$ part., maltreitos adj., preitos s.m., sojeitos s.m.

eivos /'ejvos/: çofeivos adj., trei-vos = trei P5 (?!) imperat. com pron. vos enclít. eixe l'ej/e/: feixe s.m., leixe P5 pres. subj., peixe s.m., queixe P3 pres. subj. eixo /'ej[o/: queixo P1 pres., soqueixo s.m.

ou l'ow/: formas de P1 do pres. de indicat. (dou, estou, vou) e formas de P3 do perf. de verbos da $1^{\text {a }}$ conjug. (abalou, acabou, acalçou, achou, acomendou, etc.), brou s.m., Badalhou top., Сатрои top., etc.

oua l'owa/: formas de P3 do pret. perf. $+a$ pron. pess. f. enclítico: apresentou- $a$, de) ostou- $a$, errou- $a$, etc.

ouca l'owka/: louca adj.f., pouca adj. indef. f., touca s.f.

ouco /'owko/: louco adj.m., pouco indef.m., rouco adj.m.

ouço l'owtso/: cuabouço s.m. (?), Louço antrop. m., ouço P1 pres., touço s.m.

oulhe /'ow Ke/: formas de P3 do pret. perf. + lhe pron. pess. enclítico: pesou-lhe, preguntou-lhe, rogou-lhe.

oume /'owme/: formas de P3 do pret. perf. + me pron. pess. enclítico: asseitou-me, errou-me.

ouro l'owro/: abesouro s.m., louro adj.m., mouro s.m., ouro s.m., tesouro s.m., Touro top.

ouros /'owros/: betouros s.m.pl., louros adj.m.pl., mouros s.m.pl., tesouros s.m.pl., touros s.m.pl.

ous l'ows/: babous s.m.pl., dous num. card., grous s.m.pl., sous poss. m.pl. 'seus'.

ousa /'owza/: cousa s.f., ousa P3 pres., pousa P3 pres., Sousa top.

ousas l'owzas/: cousas s.f.pl., ousas P2 pres.

ousse /'owse/: formas de P3 do pret. perf. + se pron. pess. enclítico: levantou-se, maravilhou-se, sinou-se.

ouve l'owve/: formas de $\mathrm{P} 3$ de perf. forte: houve, jouve. 


\title{
Apêndice 3: Parelhas de rimas
}

\author{
é /' $\varepsilon /, \hat{e}$ l'e/
}

é l'e/: aloé s.m., aqué adv., avé interj., Çalé top., dé $\mathrm{P} 3$ pres. subj., e conj. (?), é P3 pres., fé s.f., Loulé top., palafré s.m., pé s.m., per-é P3 pres., Salomé [Maria ] antrop. f., sé $\mathrm{P} 3$ pres.

ê l'e/: crê P3 pres. indicat., dê P3 pres. subj., ja-quê indef., mercê s.f., que conj., $q u \hat{e}$ interr., porquê interr., se conj. condic., vê P3 pres. indicat.

\section{édes /'Edes/, êdes /'edes/}

édes /'edes/: medes $\mathrm{P} 2$ pres., pedes $\mathrm{P} 2$ pres.

êdes /'edes/: o substantivo paredes s.f.pl., e formas verbais de P5 do pres. de indicat. de verbos da $2^{\mathrm{a}}$ conjug. (apõedes, ascondedes, atendedes, caedes, comedes, cometedes, conhocedes, etc.), de fut. de todos os verbos (acharedes, assanharedes, barataredes, conhoceredes, dormiredes, etc.), e de pres. de subj. da $1^{\text {a }}$ (achedes, acomendedes, afiquedes, ajudedes, alonguedes, ascoitedes, bailedes, casedes, cavalguedes, coitedes, confiedes, etc.).

\section{élo /'elo/, êlo /'elo/}

élo /'Elo/: caelo ablat. lat. de caelum / caeli s.n., 6 castelo s.m.

êlo /'elo/: Alvelo antrop. m., cabelo s.m., capelo s.m., elo pron., e várias ocorrências de infinitivo com pronome enclítico: fazê-lo, havê-lo, querê-lo, tragê-lo, vendê-lo.

êlos l'elos/: cabelos s.m., camelos s.m., elos pron. pess. [castelhanismo?], metêlos e torcê-los inf. com pron. enclít.

\section{émos /'Emos/, êmos /'emos/}

émos /'emos/: formas de P4 do perfeito forte: fezemos, houvemos.

êmos /'emos/: formas verbais de $\mathrm{P} 4$ do pres. de indicat. de verbos da $2^{\mathrm{a}}$ conjug. (acorremos, atendemos, avorrecemos, caemos, conhocemos, etc.), do pret. perf. de verbos da $2^{\text {a }}$ conjug. (aprendemos, perdemos), de fut. de indic. de todos os verbos (acabaremos, acharemos, amaremos, diremos, faremos, etc.), e de pres. de subj. da $1^{\text {a }}$ conjug. (aventuremos, bailemos, cheguemos, demos, etc.).

\section{ér /'ER/, êr /'eR/}

ér /'eR/: Alanquer top., aloguer s.m., mester s.m., molher s.f., Mompesler top., quer $\mathrm{P} 3$ pres., Santander top., segrer s.m., senher 1 s.m., senher ${ }_{2}$ s.f., volonter adv., formas do futuro de subjuntivo forte (adusser, aprouguer, disser, fezer, podér, etc.), indefinidos e advérbios compostos com a forma verbal quer (a como quer, ondequer, qualquer, etc.).

êr /'eR/: formas de infinitivo, por vezes substantivadas, ou de futuro de subjuntivo de verbos da $2^{\mathrm{a}}$ conjugação (abranger, acaecer, acender, acolher, acorrer, acreer, adoecer, adormecer, etc.). 


\section{éra l'era/, êra l'era/}

éra l'era/: era $\mathrm{P} 3$ de imperf. do vrb. seer, fera adj. f., e formas do mais-que-perf. forte (adussera, dera, dissera, fezera, houvera, podera, etc.).

êra l'era/: cera s.f., e formas do do mais-que-perfeito da $2^{\mathrm{a}}$ conjug. (bevera, cosera, morrera, nacera, perdera, etc.).

\section{éram /'Eran/, êram /'eran/}

éram /'eran/: eram P6 imperf., e formas da P6 do do do mais-que-perfeito forte (fezeram, houveram, jouveram, manteveram, poseram, preseram, trouxeram, veeram).

êram /'eran/: formas de P6 do mais-que-perf. da $2^{\text {a }}$ conjug.: encolheram, meteram.

\section{érom /'Eron/, êrom /'eron/}

érom /'eron/: formas de P6 do pret. perf. forte: creverom, derom, desfezerom, deteverom, disserom, fezerom, etc.

êrom l'eron/: formas de P6 do pret. perf. da $2^{\text {a }}$ conjug.: colherom, conhocerom, correrom, crecerom, desbolverom, mergerom, meterom, etc.

\section{ésse l'ese/, êsse l'ese/}

ésse l'ese/, êsse /'ese/: Jesse antrop. m., messe s.f., e formas do imperf. de subj. forte (désse, dissesse, estevesse, fezesse, houvesse, podesse, etc.).

êsse l'ese/: esse demonstr., e formas verbais do imperf. de subj. da $2^{\text {a }}$ conjug. (acorresse, ardesse, atendesse, bevesse, caesse, comesse, conhocesse, contecesse, creesse, doesse, etc.).

\section{éssem l'Esen/, êssem /'esen/}

éssem /'Esen/: formas de P6 do imperf. de subj. forte (dessem, detevessem, dissessem, estevessem, fezessem, houvessem, podessem, etc.).

êssem /'esen/: formas de P6 do imperf. de subj. da $2^{\mathrm{a}}$ conjug.: guarecessem, morressem.

\section{ésta /'esta/, êsta /'esta/}

ésta /'Esta/: festa s.f., gesta s.f., mãefesta adj., presta $\mathrm{P} 3$ pres., sesta s.f., testa s.f. êsta l'esta/: aquesta demonstr., besta s.f., comesta part., desta contr., vesta $\mathrm{P} 3$ pres. subj.

\section{éstes /'Estes/, êstes /'estes/}

éstes /'estes/: formas da P5 do perf. forte (composestes, déstes, dissestes, estevestes, fezestes, houvestes, etc.). 
êstes /'estes/: daquestes contr. da prep. de + aquestes demonstr., estes demonstr., e formas da P5 do perf. da $2^{\mathrm{a}}$ conjug. (aprendestes, bevestes, cometestes, conhocestes, fodestes, etc.).

\section{éu l'ew/, êu /'ew/}

éu /'єw/: Andreu antrop. m., deu P3 perf., encreu adj., eu pron. pess., Galisteu top., greu adj., Iseu antrop. f., judeu s.m., lheu adv., Mateu antrop. m., meu poss., romeu s.m., seu poss., teu poss., vergeu s.m.

$\hat{e} u$ /'ew/: sandeu adj. m., e formas de P3 do perf. de verbos da $2^{\mathrm{a}}$ conjug. (acaeсеu, acendeu, acolheu, aconteceu, acorreu, adoeceu, adormeceu, anoiteceu, apareceu, apercebeu, aprendeu, ardeu, etc.).

\section{óme l'ome/, ôme l'ome/}

óme l'ome/: come $\mathrm{P} 3$ pres., fome s.f., home s.m., ricome s.m.

ôme l'ome/: dome $\mathrm{P} 3$ pres. subj., nome s.m., tome $\mathrm{P} 3$ pres. subj.

\section{óra l'ora/, ôra l'ora/}

óra l'ora/: ancora $\mathrm{P} 3$ pres., chora $\mathrm{P} 3$ pres., demora ${ }_{1}$ s.f., demora ${ }_{2} \mathrm{P} 3$ pres., desora s.f., fora adv., hora s.f., lavora $\mathrm{P} 3$ pres., Lora top., mora ${ }_{1}$ s.f., mora ${ }_{2} \mathrm{P} 3$ pres., Mora top., ora P3 pres. e P2 imperat., ora adv., ora[-/çom] s.f.

ôra /'ola/: agora adv., Çamora top., Gomora top., senhora s.f.

\section{óres /'ores/, ôres l'ores/}

óres l'ores/: chores $\mathrm{P} 2$ pres. de subj., demores $\mathrm{P} 2$ pres. de subj.

ôres /'ores/: plural de substantivos e adjectivos terminados em -or (alvores s.m., amargores s.m., amores s.m., etc.) e de comparativos (maiores, meores, melhores), fores $\mathrm{P} 2$ do fut. subj. do vrb. ir.

\section{Referências bibliográficas}

Barbosa, J. Morais (1965): Études de phonologie portugaise (Lisboa: Junta de Investigações do Ultramar).

Bertolucci Pizzorusso, V. (1963): Le poesie di Martin Soares (Bolónia: Libreria Antiquaria Palmaverde).

Bertolucci Pizzorusso, V. (1992): As poesías de Martin Soares (Vigo: Editorial Galaxia).

Brea, M. (coord.) (1996): Lírica profana galego-portuguesa: Corpus completo das cantigas medievais, con estudio biográfico, análise retórica e bibliografía específica (Santiago de Compostela: Centro de Investigacións Lingüísticas e Literarias "Ramón Piñeiro"). 
Câmara Jr., Mattoso, J. (1976): Estrutura da língua portuguesa (Editora Vozes: Petrópolis, $7^{\mathrm{a}}$ ed.).

Câmara Jr., Mattoso, J. (1977): Para o estudo da fonêmica portuguesa (Rio de Janeiro: Padrão Livraria Editora, $2^{\mathrm{a}}$ ed.).

Cunha, C. Ferreira da (1982): Estudos de Versificação Portuguesa (Séculos XIII a XVI) (Paris: Fundação Gulbenkian).

Cunha, C. [Ferreira da] (1988): "Sobre a evolução ortoépica das formas ledo e leda", em Kremer, D. (ed.): Homenagem a Joseph M. Piel por ocasião do seu 85. aniversário: 221-236 (Tubinga: Max Niemeyer Verlag).

Cunha, C. Ferreira da (1991): «Valor das grafias -eu e -eo do século XIII ao século XVI», em VV.AA., Estudos Portugueses: Homenagem a Luciana Stegagno Picchio: 913-927 (Lisboa: DIFEL [Difusão Editorial, Lda.]).

D'Heur, Jean-Marie (1973): «Nomenclature des troubadours galiciens-portugais (XII ${ }^{\mathrm{e}}$ $\mathrm{XIV}^{\mathrm{e}}$ siècles), table de concordance de leurs chansonniers, et liste des incipit de leurs compositions», em: Arquivos do Centro Cultural Português 7: 17-100 [= D'Heur, Jean-Marie (1975): Recherches internes sur la lyrique amoureuse des troubadours galiciens-portugais (XII-XIV siècles): contribution a l'étude du «corpus des troubadours»: 10-93 (Liège)].

Ferreiro, M. (1997): Gramática histórica galega, II: Lexicoloxía (Santiago de Compostela: Edicións Laiovento).

Lang, Henry R. (1894): Das Liederbuch des Königs Denis von Portugal zum ersten Mal vollständig herausgegeben und mit Einleitung, Anmerkungen und Glossar versehen (Halle a. S.: Niemeyer).

Lapa, M. Rodrigues (1970): Cantigas d'escarnho e de mal dizer dos cancioneiros medievais galego-portugueses: $2^{a}$ edição, revista e acrescentada (Vigo: Editorial Galaxia).

Lapa, M. Rodrigues (1981): Lições de Literatura Portuguesa: Época Medieval; $10^{a}$. edição revista pelo autor (Coimbra: Coimbra Editora).

Lapa, M. Rodrigues (1982): Miscelânea de Língua e Literatura Portuguesa Medieval (Coimbra: Imprensa da Universidade).

Maia, Clarinda de Azevedo (1986): História do Galego-Português: Estudo linguístico da Galiza e do Noroeste de Portugal desde o século XIII ao século XVI (Com referência à situação do galego moderno) (Coimbra: Instituto Nacional de Investigação Científica).

Mettmann, W. (1989): Alfonso X, el Sabio, Cantigas de Santa María: Edición, introducción y notas de Walter Mettmann. 3 tomos. Tomo 3. (Madrid: Editorial Castalia). 
Montero Santalha, J.-M. (2000): As rimas da poesia trovadoresca galego-portuguesa: catálogo e análise (Tese de doutoramento inédita. Universidade da Corunha. Área de Filologia Galega e Portuguesa).

Mussafia, A. (1983): «Sull' antica metrica portoghese: Osservazioni», em Scritti di filologia e linguistica a cura di Antonio Daniele e Lorenzo Renzi: 302-340 (Pádua: Editrice Antenore).

Nunes, José Joaquim (1926-1928): Cantigas d'Amigo dos Trovadores GalegoPortugueses. Edição crítica, acompanhada de introdução, comentário, variantes e glossário. 3 volumes. (Coimbra: Imprensa da Universidade).

Nunes, José Joaquim (1932): Cantigas d'Amor dos Trovadores Galego-Portugueses. Edição crítica, acompanhada de introdução, comentário, variantes, e glossário (Coimbra: Imprensa da Universidade).

Riquer, M. (1983): Los trovadores: historia literaria y textos (Barcelona: Editorial Ariel).

Tavani, G. (1967): Repertorio metrico della lirica galego-portoghese (Roma: Edizioni dell'Ateneo).

Víñez, A. (1989): «Rimario del Cancioneiro da Ajuda», Cuadernos de Filología Románica, 1: 55-143.

Víñez, A. / Sáez, J. (1997): “Un rimario de las cantigas de amigo”, em Lucía Megías, J. M. (ed.): Actas del VI Congreso Internacional de la Asociación Hispánica de Literatura Medieval (Alcalá de Henares, 12-16 de septiembre de 1995). Vol 2: 1.589-1.598 (Alcalá de Henares: Universidad de Alcalá). 